Supporting Information (SI)

\title{
Switching on H-Tunneling through Conformational Control
}

José P. L. Roque, ${ }^{1}$ Cláudio M. Nunes, ${ }^{1} *$ Luís P. Viegas,${ }^{1}$ Nelson A. M. Pereira, ${ }^{1}$ Teresa M. V. D. Pinho e Melo, ${ }^{1}$ Peter R. Schreiner, ${ }^{2}$ and Rui Fausto ${ }^{1}$

${ }^{1}$ University of Coimbra, CQC, Department of Chemistry, 3004-535 Coimbra, Portugal

${ }^{2}$ Institute of Organic Chemistry, Justus Liebig University, Heinrich-Buff-Ring 17, 35392 Giessen, Germany

* Email: cmnunes@qui.uc.pt

\section{TABle OF Contents}

1. Experimental and Computational Methods

2. Figures 


\section{Experimental and Computational Methods}

\section{Synthesis of 3-fluoro-2-hydroxyphenylazide 9}

General: Commercial reagents were used as purchased. ${ }^{1} \mathrm{H}$ and ${ }^{13} \mathrm{C}$ Nuclear Magnetic Resonance (NMR) spectra were recorded on an NMR spectrometer Bruker Avance III operating at 400 and $100 \mathrm{MHz}$, respectively. Chemical shifts are referred to the residual signal of DMSO- $\mathrm{d}_{6},{ }^{1} \mathrm{H}$ NMR $\left(\delta_{\mathrm{H}}=2.50\right)$ and ${ }^{13} \mathrm{C}$ NMR $\left(\delta_{\mathrm{C}}=39.5\right)$, or to the internal standard tetramethylsilane (TMS). Chemical shifts are given in parts per million ( $\mathrm{ppm}$ ) relative to TMS and coupling constants $J$ are given in Hertz. Thin-layer chromatography (TLC) was carried out on silica gel $60 \mathrm{~F}_{254}$ plates (AL TLC $20 \times 20)$. Column chromatography was performed on Silica Gel $60(0.04-0.063 \mathrm{~mm})$. Highresolution mass spectra (HRMS) were obtained with a Waters Micromass VG Autospec M ESI-TOF spectrometer.

Synthesis: The synthesis of 3-fluoro-2-hydroxyphenylazide 9 (Scheme S1) was carried out based on a procedure described in the literature for the preparation of other azidophenol derivatives. ${ }^{1}$

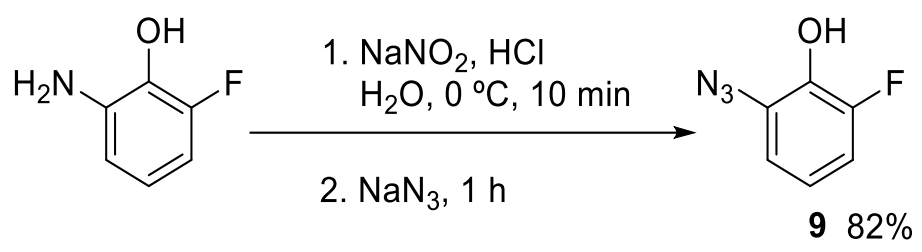

Scheme S1. Synthesis of 3-fluoro-2-hydroxyphenylazide 9.

Concentrated $\mathrm{HCl}(37 \% \mathrm{v} / \mathrm{v}, 1.1 \mathrm{~mL})$ was added dropwise to a suspension of 2-amino6-fluorophenol $(0.5 \mathrm{~g}, 3.9 \mathrm{mmol})$ in water $(12.5 \mathrm{~mL})$, at $0{ }^{\circ} \mathrm{C}$, followed by the addition of a solution of $\mathrm{NaNO}_{2}(0.27 \mathrm{~g}, 3.9 \mathrm{mmol}, 1 \mathrm{eq})$ in water $(1.2 \mathrm{~mL})$. After $10 \mathrm{~min}$, the cooling bath was removed and the reaction mixture was allowed to warm to room temperature. Sodium azide $(0.31 \mathrm{~g}, 4.8$ mmol and $1.2 \mathrm{eq}$ ) was added portionwise and, after stirring at room temperature for $1 \mathrm{~h}$, the reaction mixture was extracted with EtOAc $(25 \mathrm{~mL})$, the organic layer washed with brine $(25 \mathrm{~mL})$, water $(25 \mathrm{~mL})$ and dried over anhydrous sodium sulphate. The solvent was removed by evaporation followed by purification of the crude product by flash chromatography [ethyl acetate/hexane (1:2)]. The azide 9 was obtained as a light brown solid in $82 \%$ yield $(0.49 \mathrm{~g}, 3.2$ mmol). 
Characterization of 9: ${ }^{1} \mathrm{H}$ NMR (400 MHz, DMSO-d $)$ ): $\delta$ (ppm) 10.21 (bs, 1H, OH), 7.04-6.97 $(\mathrm{m}, 1 \mathrm{H}, \mathrm{Ph}-\mathrm{H}), 6.86-6.79$ (m, 2H, Ph-H). ${ }^{13} \mathrm{C}$ NMR (100 MHz, DMSO-d $): \delta$ (ppm) $151.9(\mathrm{~d}$, $\left.J_{\mathrm{CF}}=239.5 \mathrm{~Hz}\right), 138.1\left(\mathrm{~d}, J_{\mathrm{CF}}=16.7 \mathrm{~Hz}\right), 128.6\left(\mathrm{~d}, J_{\mathrm{CF}}=4.8 \mathrm{~Hz}\right), 119.4\left(\mathrm{~d}, J_{\mathrm{CH}}=8.4 \mathrm{~Hz}\right), 116.3$ $\left(\mathrm{d}, J_{\mathrm{CH}}=2.7 \mathrm{~Hz}\right), 112.6\left(\mathrm{~d}, J_{\mathrm{CH}}=18.8 \mathrm{~Hz}\right)$. HRMS $\left(\mathrm{ESI}^{+}, m / z\right)$ calcd for $\mathrm{C}_{6} \mathrm{H}_{4} \mathrm{FN}_{3} \mathrm{ONa}(\mathrm{M}+\mathrm{Na})^{+}$ $=176.0231$, found 176.0232 .

Matrix Isolation IR Spectroscopy: A sample of 3-fluoro-2-hydroxyphenylazide 9 was placed in a glass tube, which was then connected to a closed-cycle helium cryostat (Advanced Research Systems DE-202) through a stainless-steel needle valve (SS-4BMRG NUPRO). Possible traces of volatile impurities were removed by pumping the sample through the cryostat at room temperature. Monomeric matrices were prepared by co-deposition of vapors of $\mathbf{9}$ at room temperature and a large excess of nitrogen gas (N50, Air Liquide) onto a cold (10 K) CsI optical substrate. The temperature of the CsI window was directly measured by a silicon diode, connected to a digital controller (LakeShore 311), and stabilized with an accuracy of $0.1 \mathrm{~K}$.

Infrared spectra were recorded using a Thermo Nicolet 6700 Fourier transform infrared (FTIR) spectrometer, equipped with a Mercury Cadmium Telluride (MCT-B) detector (cooled with liquid nitrogen) and a $\mathrm{KBr}$ beam splitter, for the mid-IR range (4000-400 $\mathrm{cm}^{-1}$ ), or a Indium Gallium Arsenide (InGaAs) detector and $\mathrm{a} \mathrm{CaF}_{2}$ beam splitter, for the near-IR range (7500-4000 $\mathrm{cm}^{-1}$ ). When there was the need to protect the sample from part of the infrared light, the mid-IR spectra were collected in the range $1580-400 \mathrm{~cm}^{-1}$ by using a long-pass filter (Spectrogon LP$6300 \mathrm{~nm}$, transmission cut-off value $\sim 1587 \mathrm{~cm}^{-1}$ ) placed between the spectrometer light source and the sample. The infrared spectra were recorded with resolution 0.5 or $2 \mathrm{~cm}^{-1}$ in the mid-IR and near-IR ranges, respectively. To reduce the interference from atmospheric $\mathrm{H}_{2} \mathrm{O}$ and $\mathrm{CO}_{2}$, a stream of dry and $\mathrm{CO}_{2}$ filtered-off air was used to continuously purge the optical path of the spectrometer.

UV and Near-IR Irradiation Experiments: The matrix-isolated species were irradiated through the outer $\mathrm{KBr}$ window of the cryostat using a frequency-tunable narrowband light [full width at half-maximum (fwhm) of $\sim 0.2 \mathrm{~cm}^{-1}$ ] generated by a frequency-doubled signal (UV range) or an idler (near-IR range) beam of an optical parametric oscillator (Spectra Physics Quanta-Ray MOPO-SL) pumped with a pulsed Nd:YAG laser (Spectra-Physics PRO-230: output power $\sim 4.4 \mathrm{~W}$; wavelength $=355 \mathrm{~nm}$; duration $=10 \mathrm{~ns}$; repetition rate $=10 \mathrm{~Hz}$ ). 
IR Spectra and Thermochemistry Computations: The geometry optimizations and harmonic frequency computations were performed for the most relevant stationary points of 9, 9', 10, and 11 at the B3LYP/6-311+G(2d,p) level of theory, ${ }^{2-5}$ using the Gaussian 16 software package. ${ }^{6}$ All computations were performed using tight optimization criteria. The nature of each stationary point was inspected by the analysis of the Hessian matrices. To take into consideration the neglected anharmonic effects, the limitations of the implemented methods and the limitations of the basis set, the harmonic vibrational frequencies were scaled by a factor of 0.979 or 0.955 for wavenumbers above or below $2500 \mathrm{~cm}^{-1}$, respectively. ${ }^{7}$ The scaled harmonic vibrational frequencies and respective absolute intensities were used to simulate the IR spectra by convoluting each peak with a Lorentzian function having an fwhm of $2 \mathrm{~cm}^{-1}$. Anharmonic frequency computations for $\mathbf{9}$ and $\mathbf{a}-{ }^{3} \mathbf{1 0}$ were carried out at the B3LYP/6-311+G(2d,p) level of theory, using the fully automated generalized second-order vibrational perturbative theory (GVPT2), as implemented in Gaussian 16. ${ }^{8-10}$ Thermochemistry computations for 9 and 9' were carried out at the B3LYP/6-311+G(2d,p) and CBS-QB3 ${ }^{11,12}$ levels of theory. The computed data were then used to estimate the relative Gibbs energy at $298.15 \mathrm{~K}\left(\Delta \mathrm{G}_{298 \mathrm{~K}}\right)$ for the different conformers and their room temperature Boltzmann populations.

Normal mode analysis: The theoretical normal modes of $\mathbf{a}^{-}{ }^{3} \mathbf{1 0}$ and $\mathbf{Z}-\mathbf{1 1}$ were analyzed by carrying out potential energy distribution (PED) calculations. The calculated force constants with respect to Cartesian coordinates, obtained from the Gaussian 16 computations, were transformed into the force constants with respect to internal coordinates, which allowed the PED analysis to be carried out as described elsewhere. ${ }^{13}$ The set of internal coordinates used for $\mathbf{a}-{ }^{3} \mathbf{1 0}$ and $\mathbf{Z}-\mathbf{1 1}$ were defined as recommended by Pulay et al. ${ }^{14}$ and are given in Tables S2 and S3, respectively. The atom numberings of $\mathbf{a}^{3}{ }^{3} \mathbf{1 0}$ and $\mathbf{Z}-\mathbf{1 1}$, used for the definition of the internal coordinates, are shown in Figure S5. The vibrational assignment of $\mathbf{a}^{3} \mathbf{1 0}$ and $\mathbf{Z - 1 1}$ and the obtained PED matrices are presented in Tables S4 and S5, respectively.

MECP Computations: Due to the open-shell nature of the nitrene species, the potential energy surface (PES) connecting $\mathbf{a}^{-3} \mathbf{1 0}$ and $\mathbf{Z - 1 1}$ was preliminarily screened at the multiconfigurational CASSCF(8,8)/6-31G(d) level of theory using the Gaussian 16 software package. ${ }^{6}$ An eight electron - eight orbital $(8,8)$ complete active space (CAS) was used for all species. For nitrene 10, 
the defined CAS consists of seven out-of-plane $\pi / \pi^{*}$ orbitals (A") and one in-plane p atomic orbital (A') (Figure S6). ${ }^{15}$ We computed the minimum corresponding to two conformers of the triplet ground-state (TGS) nitrene $\left(\mathbf{a}-{ }^{3} \mathbf{1 0}\right.$ and $\left.\mathbf{s}^{3}{ }^{3} \mathbf{1 0}\right)$, two conformers of the open-shell singlet (OSS) nitrene (a- ${ }^{\mathrm{OSS}} \mathbf{1 0}$ and $\left.\mathbf{s}_{-}{ }^{\mathrm{OSS}} \mathbf{1 0}\right)$, and one conformer of the closed-shell singlet (CSS) nitrene $\left(\mathbf{a}^{-{ }^{C S S}} \mathbf{1 0}\right)$. The putative $\mathbf{s}^{-}{ }^{\mathrm{CSS}} \mathbf{1 0}$ conformer, with a $\mathrm{OH}$ group facing the reactive nitrene center could not be located as a minimum. For the imino Z-11, the defined CAS consists of eight out-of-plane $\pi / \pi^{*}$ orbitals (A") (Figure S6). We computed the minimum corresponding to the singlet groundstate imino $(\mathbf{Z}-\mathbf{1 1})$ and to triplet state imino $\left(\mathbf{Z}^{-}{ }^{3} \mathbf{1 1}\right)$.

The nitrene $\mathbf{s}^{-}{ }^{3} \mathbf{1 0}$ and imino $\mathbf{Z}-\mathbf{1 1}$ have different ground state multiplicities (triplet and singlet) and, therefore, the existence of a minimum-energy crossing point (MECP) connecting both species was investigated. An initial MECP search was performed using the so-called partial optimization method. In this case, by running relaxed PES scans as a function of the $\mathrm{r}(\mathrm{OH})$ coordinate (i.e., optimizing all internal coordinates while incrementally fixing the $\mathrm{OH}$ bond distance), starting from the minima found before; $\mathbf{s}^{3}{ }^{3} \mathbf{1 0}, \mathbf{s}^{-}{ }^{\text {OSS }} \mathbf{1 0}, \mathbf{Z}-\mathbf{1 1}$, and $\mathbf{Z}-{ }^{3} \mathbf{1 1}$ (Figure S7). The increment used between each scan step was $0.02 \AA$ (regarding the $\mathrm{OH}$ bond distance), a small value to avoid discontinuities in the active space. The partial optimization method is a modest approximation for the search of a MECP because all the coordinates except the $\mathrm{r}(\mathrm{OH})$ are optimized separately in each surface, rather than converging together. ${ }^{16,17}$ Nonetheless, this approach provides useful insights into the PES investigated. First, it shows the dissociative character of the $\mathbf{s}^{-}{ }^{\mathrm{CSS}} \mathbf{1 0}\left({ }^{1} \mathrm{~A}^{\prime}\right)$ surface along the $\mathrm{r}(\mathrm{OH})$ coordinate as connecting to singlet $\mathbf{Z}-\mathbf{1 1}$, thus explaining the lack of success in finding the $\mathbf{s}_{-}{ }^{\mathrm{CSS}} \mathbf{1 0}$ minimum. Second, it shows that $\mathbf{s}_{-}{ }^{\text {OSS }} \mathbf{1 0}$ $\left({ }^{1} \mathrm{~A}^{\prime \prime}\right)$ surface is parallel to $\mathbf{s}^{3}{ }^{3} \mathbf{1 0}\left({ }^{3} \mathrm{~A}^{\prime \prime}\right)$ surface, and therefore, the existence of a MECP between these surfaces is unlikely. Finally, it shows that it is likely that there exists an MECP at the crossing between the triplet $\mathrm{A}^{\prime \prime}$ and CSS A' surfaces, directly connecting $\mathbf{s}^{3}{ }^{3} \mathbf{1 0}$ and $\mathbf{Z}-\mathbf{1 1}$. A subsequent full MECP search was performed using a global optimization algorithm employing the EasyMECP software package, ${ }^{18}$ which is a python script developed based on the work of Harvey et al. ${ }^{19}$ This software was used as default, requiring solely the inclusion of an energy-parse code to allow reading the data of CASSCF computations performed in Gaussian 16. The structure on the singlet surface previously obtained by the partial optimization method, near the crossing between triplet A" and CSS A' surfaces, was used as the input geometry. The initial guess active space orbitals of the input structure at triplet and singlet multiplicities were those of the active space orbitals of 
a- ${ }^{3} \mathbf{1 0}$ and $\mathbf{Z}-\mathbf{1 1}$, respectively. Using this method, one MECP was found. Vibrational analysis on the seam of the MECP was carried out using the GLOWfreq software package. ${ }^{20}$ Here, two Hessian matrices obtained on each of the diabatic surfaces are combined in one effective Hessian. Then the motion orthogonal to the crossing seam is projected out and the effective Hessian is finally diagonalized to provide the effective vibrational frequencies of the MECP. Finally, intrinsic reaction coordinate (IRC) computations with each multiplicity were performed by following the steepest descendent path from the optimized MECP structure, which confirms that the found MECP connects $\mathbf{a}^{-}{ }^{3} \mathbf{1 0}$ and $\mathbf{Z}-\mathbf{1 1}$.

To properly account for dynamic electron correlation and to obtain more reliable energies, CASSCF computations are usually augmented by single point computations using a method such as CASPT2. However, the geometry of an MECP can be extremely dependent on the level of theory. Because the MECP depends on the relative positions of two surfaces, changing the level of theory from CASSCF to CASPT2 for performing single point calculations can shift the surfaces relative to one another and lead to unreliable energy values. ${ }^{19,21}$ Alternatively, one can perform the MECP search using a time affordable computational method that already includes dynamic electron correlation such as DFT, as long as the method chosen is adequate for the system being studied (e.g., the species to be computed do not possess multiconfigurational character). The need to use multiconfigurational methods for a correct description of most nitrenes species is mainly because of their OSS states. ${ }^{22}$ Triplet ground-state arylnitrenes, such as the $\mathbf{s}^{3}{ }^{3} \mathbf{1 0}$, are properly and reliably described by DFT computations. The product $\mathbf{Z - 1 1}$ is a closed-shell singlet system and there is no need for using multiconfigurational computations. Since the MECP found during the CASSCF search is at the crossing between a triplet and a singlet surface, connecting the $\mathbf{s}^{-}{ }^{3} \mathbf{1 0}$ and Z-11, it is reasonable to assume that this MECP can be correctly described by DFT methods. Thus, we performed B3LYP/6-311+G(2d,p) relaxed PES scans along the $\mathrm{r}(\mathrm{OH})$ coordinate and obtained qualitatively identical results to those performed at the CASSCF level (compare Figures S7 and S8). Accordingly, the partial optimization method carried out at the B3LYP level also suggests the existence of an MECP at a crossing between the triplet A" and CSS A' surfaces, connecting the $\mathbf{s}^{3} \mathbf{1 0}$ and Z-11 species. A subsequent full MECP search was performed at the B3LYP/6-311+G(2d,p) level, according to the method described above for the similar search performed at the $\operatorname{CASSCF}(8,8) / 6-31 \mathrm{G}(\mathrm{d})$ level. Additional details are provided in the main text. 
Tunneling Rate Computations: The transformation of triplet $\mathbf{s}^{-3} \mathbf{1 0}$ to singlet $\mathbf{Z - 1 1}$ is a spinforbidden reaction involving $\mathrm{H}$-atom tunneling. Two different mechanisms can be envisioned: (i) A two-step mechanism involving an $\mathrm{H}$-atom QMT on the triplet surface from $\mathbf{s}^{3} \mathbf{1 0}$ to $\mathbf{Z}-{ }^{3} \mathbf{1 1}$ followed by intersystem crossing (ISC) to singlet ground state $\mathbf{Z - 1 1}$; (ii) A single-step mechanism involving an H-atom QMT through crossing triplet and single surfaces from ${ }^{3} \mathbf{1 0}$ to $\mathbf{Z}-\mathbf{1 1}$.

(i) The H-atom QMT rate on the triplet surface (first hypothesis) was computed by the WentzelKramers-Brillouin (WKB) approximation. ${ }^{23-25}$ According to this model, the probability $P(E)$ of tunneling is given by:

$$
P(E)=\mathrm{e}^{-\pi^{2} w \sqrt{2 m\left(V_{0}-E\right)} / h},
$$

where $\mathrm{m}$ is the mass of the particle tunneling through a barrier with height $V_{0}$ and width $w,\left(V_{0}-E\right)$ is the energy difference of the particle E with respect to the top of the barrier, and $h$ is Planck's constant. Tunneling rates are given by the product of the tunneling probability and the frequency of attempts (i.e., the frequency of the normal mode associated to the reaction coordinate). To obtain the parameters of the barrier, intrinsic reaction coordinate (IRC) profiles connecting $\mathbf{s}^{3} \mathbf{1 0}$ to $\mathbf{Z}-{ }^{3} \mathbf{1 1}$ were computed at the B3LYP/6-311+G(2d,p). The strictly electronic energy profiles were then corrected by the zero-point vibrational energy of the stationary points. After this procedure, the relative barrier height $\left(V_{0}-E\right)$ was computed to be $98.2 \mathrm{~kJ} \mathrm{~mol}^{-1}$ and the barrier width $w$ to be 2.10 bohr (Figure S9). Using equation 1.1, the tunneling probability was estimated to be $1.49 \times 10^{-17}$. Considering the computed $\delta(\mathrm{OH})=1361 \mathrm{~cm}^{-1}$ of $\mathbf{s}^{-3} \mathbf{1 0}$ as the frequency of attempts, the tunneling rate was estimated to be $6.07 \times 10^{-4} \mathrm{~s}^{-1}$ (half-life of $1.14 \times 10^{3} \mathrm{~s}$ ).

(ii) The H-atom QMT rate through crossing triplet and singlet surfaces (second hypothesis) was computed with the weak coupling (WC $)^{26-28}$ formulation of non-adiabatic transition state theory (NA-TST), ${ }^{26,29-34}$ which we have employed very recently for the calculation of spin-forbidden QMT rate constants. ${ }^{21,35}$ The reader is referred to those papers for a detailed description of the procedure. By running the GLOWfreq code with data obtained from B3LYP/6-311+G(2d,p) computations (see above), we obtain the quantities required by the NA-TST equation such as the norm of the difference of the gradients on the two surfaces at the MECP $\left(1.26 \times 10^{-1}\right.$ hartree

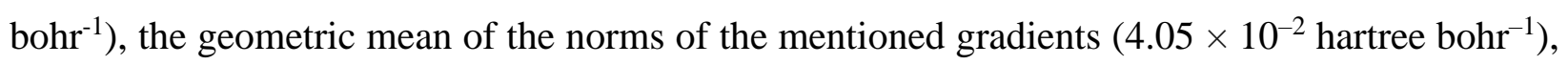
the zero-point energy at the MECP (0.0840 hartrees, which leads to an MECP barrier of $\sim 42.1 \mathrm{~kJ}$ $\mathrm{mol}^{-1}$ relative to $\mathbf{s}^{3}{ }^{3} \mathbf{1 0}\left[\sim 39.3 \mathrm{~kJ} \mathrm{~mol}^{-1}\right.$ relative to $\left.\left.\mathbf{a -}{ }^{3} \mathbf{1 0}\right]\right)$ and the reduced mass of the mode orthogonal to the crossing seam surface (11.2 amu). However, as suggested by Harvey, ${ }^{29}$ we can 
expect that in the deep tunneling regime of this particular reaction, the process of breaking an $\mathrm{O}-\mathrm{H}$ bond and forming an $\mathrm{N}-\mathrm{H}$ bond will be dominated by the motion of the hydrogen atom alone. Therefore, instead of using $11.2 \mathrm{amu}$ for the reduced mass, we have used a value of $1 \mathrm{amu}$. The spin-orbit coupling, which also enters the NA-TST equation, was calculated at the B3LYP/6$311+\mathrm{G}(2 \mathrm{~d}, \mathrm{p})$ level with MolSOC ${ }^{36-38}$ and found to be $21.17 \mathrm{~cm}^{-1}$. With these data, the NA-TST rate constant at $10 \mathrm{~K}$ yields $26.7 \mathrm{~s}^{-1}$ (half-life of $0.026 \mathrm{~s}$ ). 


\section{Figures}
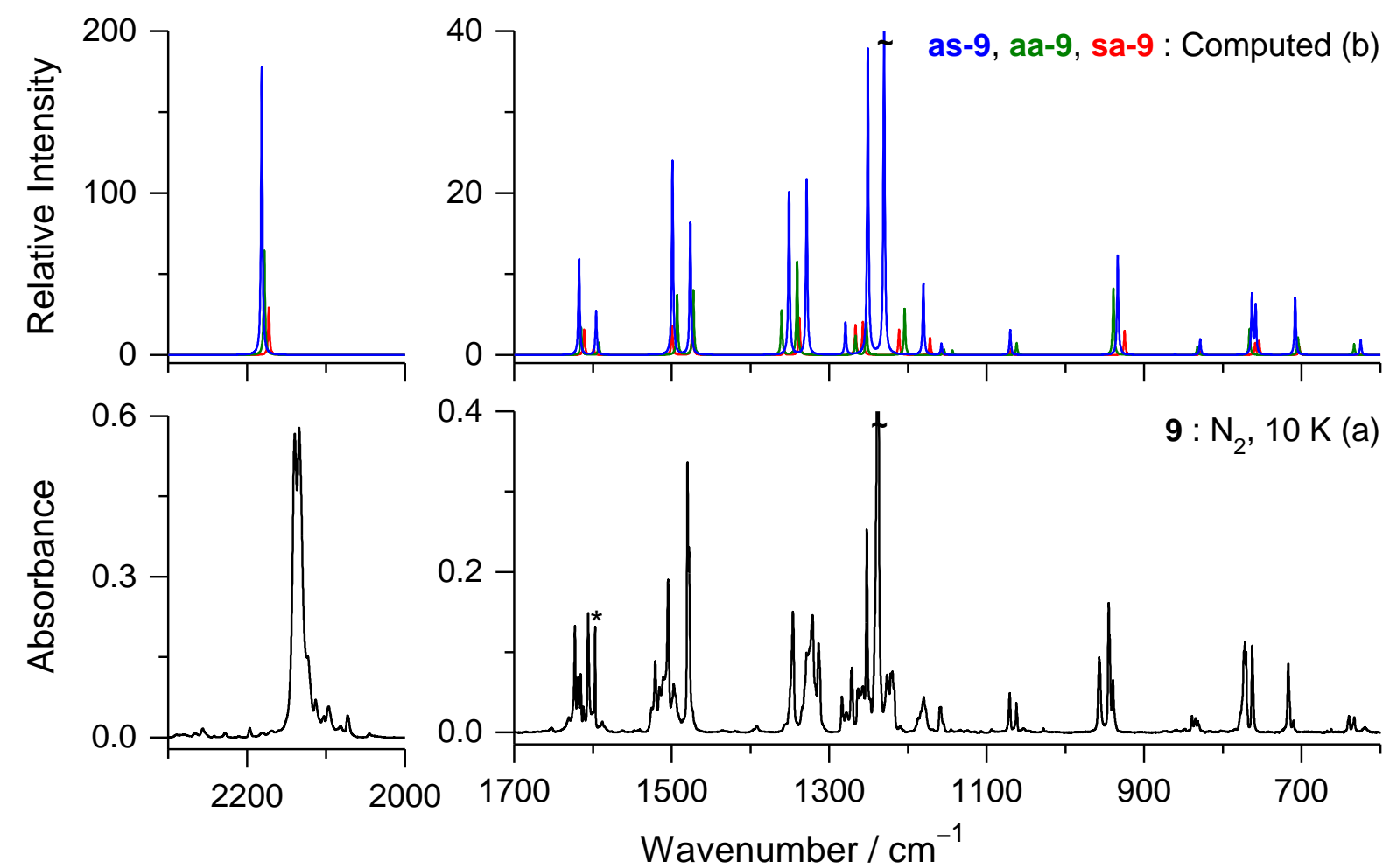

Figure S1. (a) Experimental IR spectrum of 3-fluoro-2-hydroxyphenylazide 9 in a nitrogen matrix at $10 \mathrm{~K}$. The asterisk symbol indicates contribution from monomeric water. (b) IR spectrum of 9 computed at the B3LYP/6-311+G(2d,p) level of theory considering the population of as-9, aa-9 and sa-9 conformers in a ratio of 66:11:23 (see Table S1). 

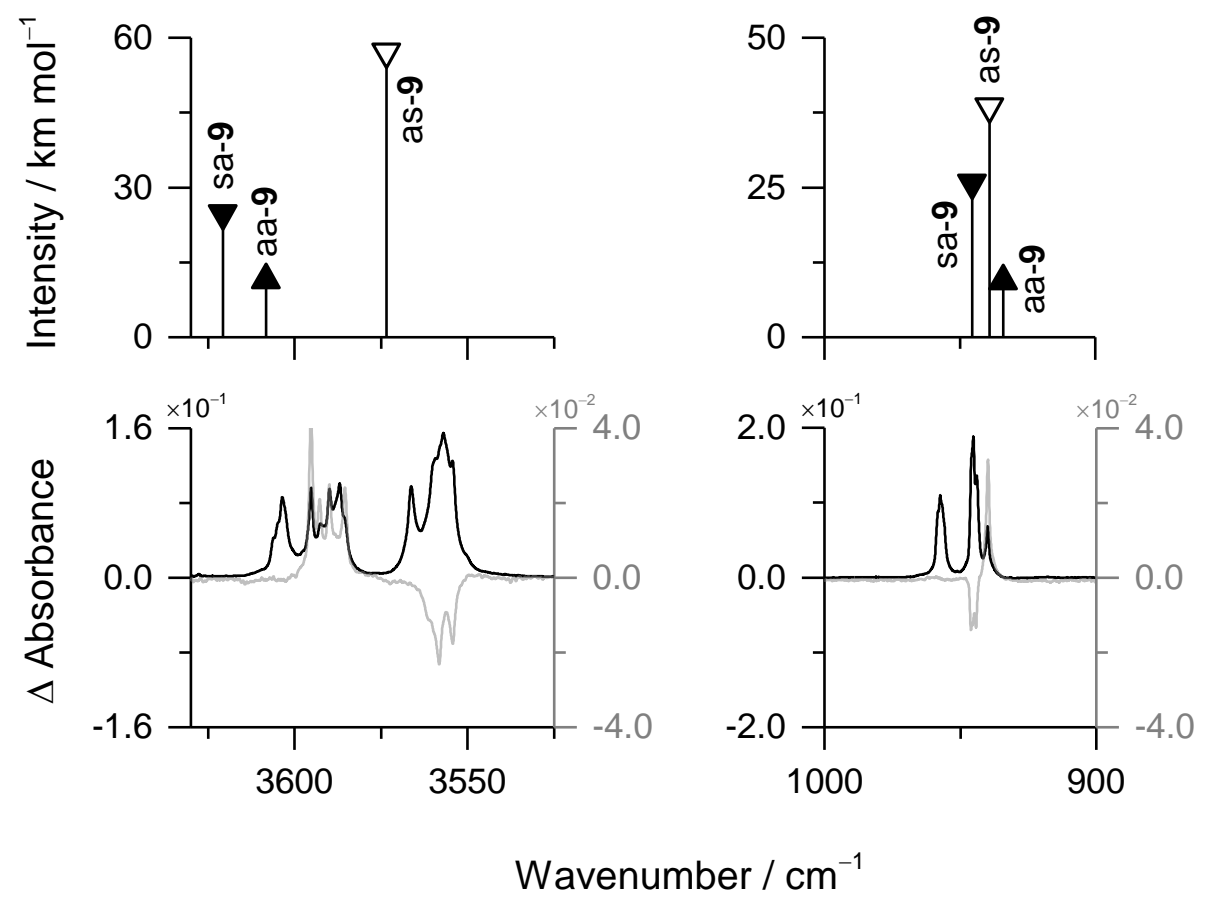

(b)

(a)

Wavenumber $/ \mathrm{cm}^{-1}$

Figure S2. (a) Selected regions showing the mid-IR spectrum collected immediately after the deposition of 3-fluoro-2-hydroxyphenylazide 9 in a nitrogen matrix at $10 \mathrm{~K}$ (back line) and the corresponding difference IR spectrum resulting from irradiation at $6938 \mathrm{~cm}^{-1}(60 \mathrm{~mW}, 1 \mathrm{~h}$ ) (gray line). Negative bands indicate the consumption of as-9 and positive bands the production of aa-9. The conformer sa-9 remains unchanged. (b) Anharmonic wavenumbers and IR intensities computed at the B3LYP/6-311+G(2d,p) level for the as-9, aa-9 and sa-9 conformers, considering the population ratio of $66: 11: 23$, respectively. 


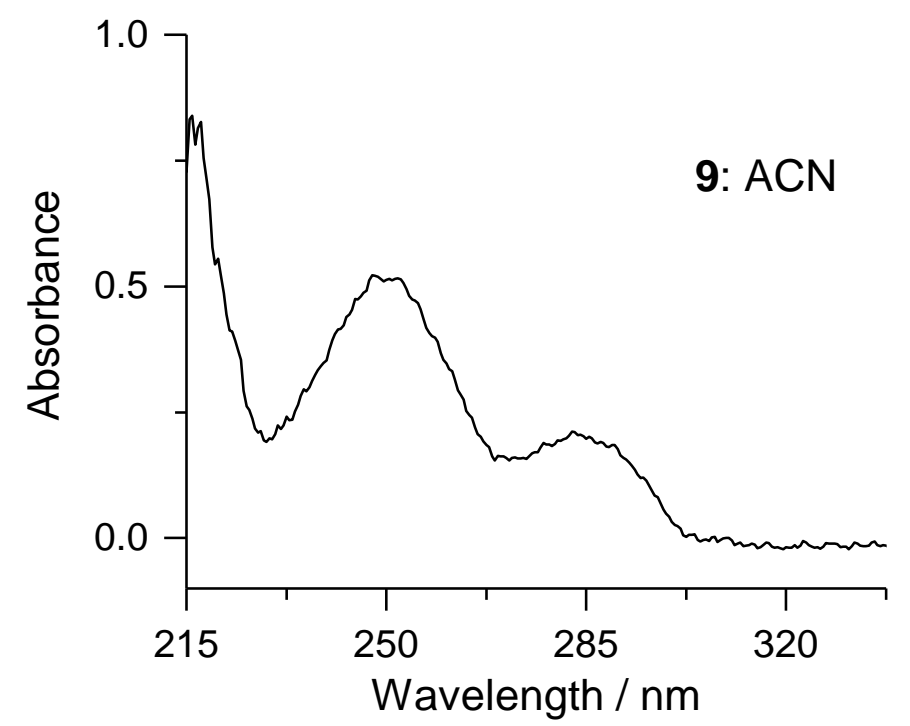

Figure S3. UV-Vis spectrum of 3-fluoro-2-hydroxyphenylazide (9) in acetonitrile (ACN). The spectrum was recorded in a Shimadzu UV2501-PC at room temperature.

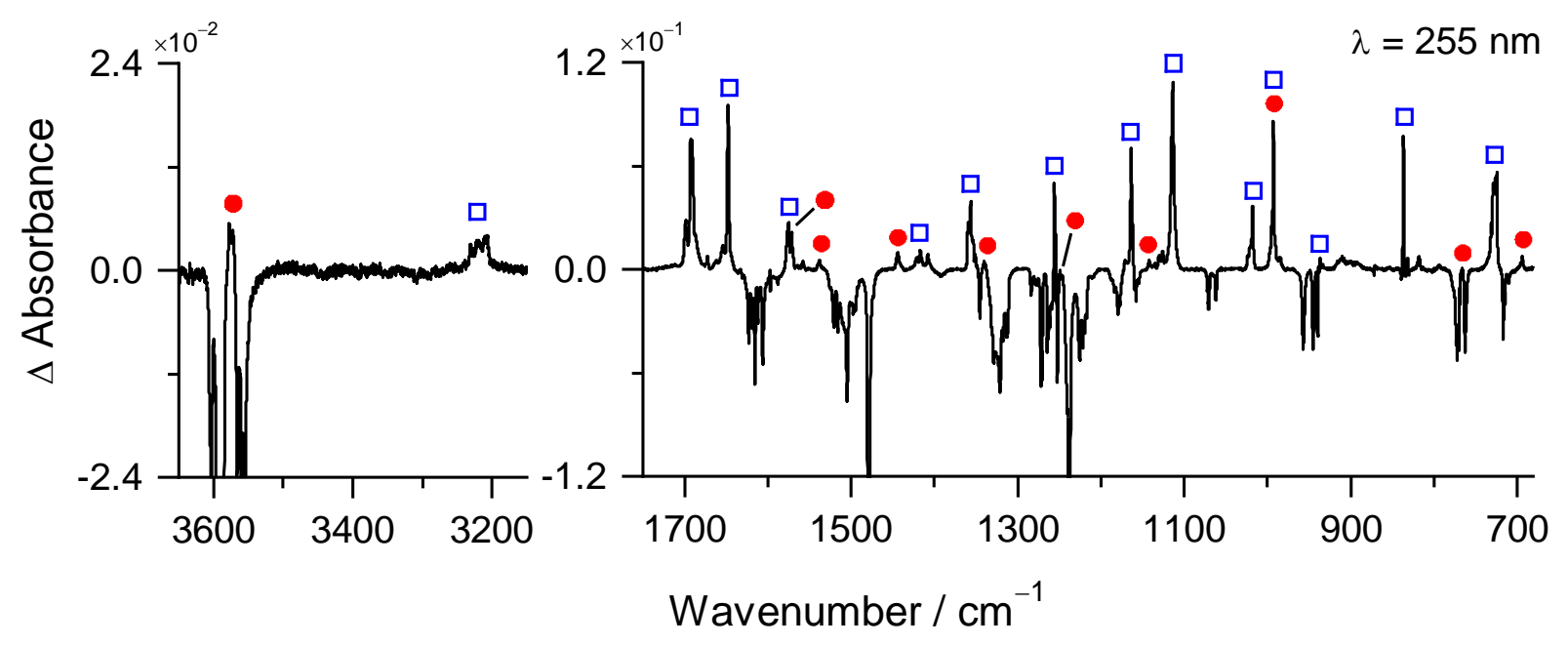

Figure S4. Experimental difference IR spectrum showing changes after irradiation of 9 at $\lambda=255 \mathrm{~nm}(1 \mathrm{~min}, 20 \mathrm{~mW})$. Negative bands are due to the consumption of 9 and the positive bands are due to the production of $\mathbf{a}^{3} \mathbf{1 0}$ ( $\bullet$, closed red circles) and Z-11 ( $\square$, open blue squares). Further details regarding the identification of $\mathbf{a}-{ }^{3} \mathbf{1 0}$ and $\mathbf{Z - 1 1}$ are discussed in the main text. 

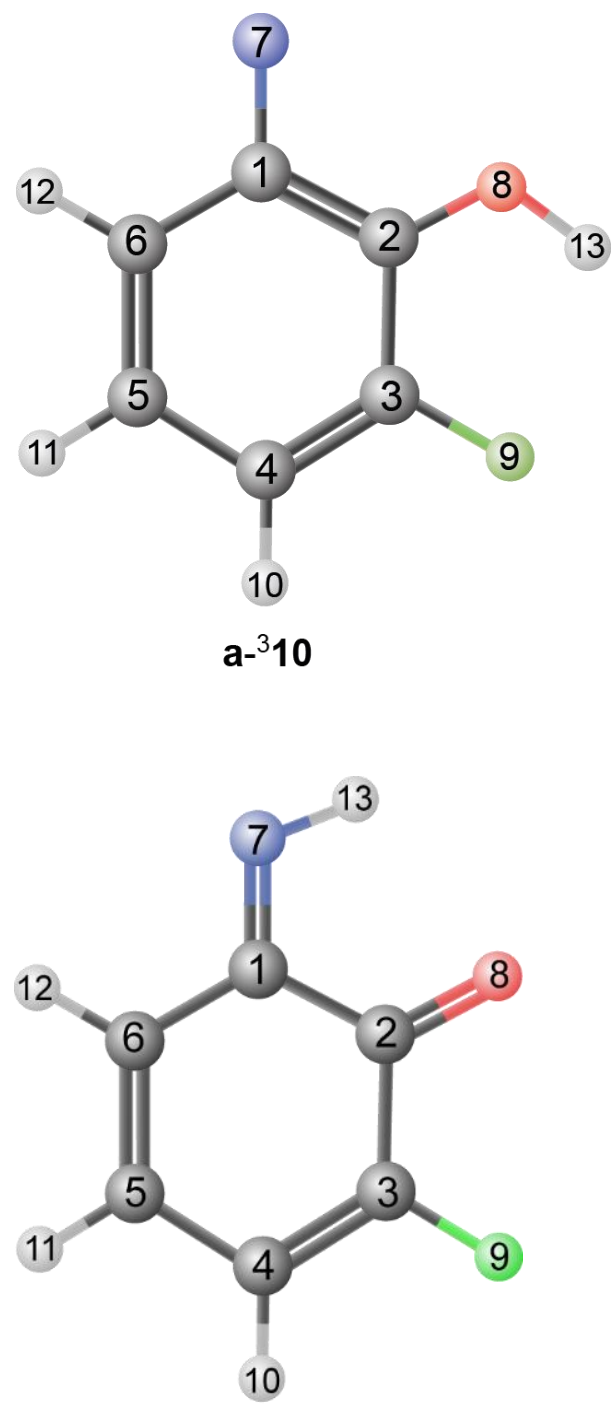

Z-11

Figure S5. Geometry and atom numbering of triplet anti-3-fluoro-2-hydroxyphenylnitrene a- ${ }^{3} \mathbf{1 0}$ and (Z)-2-fluoro-6-iminocyclohexa-2,4-dienone Z-11 used for the definition of internal coordinates. Color codes: blue - nitrogen, red - oxygen, green - fluor, gray - carbon, white hydrogen. 


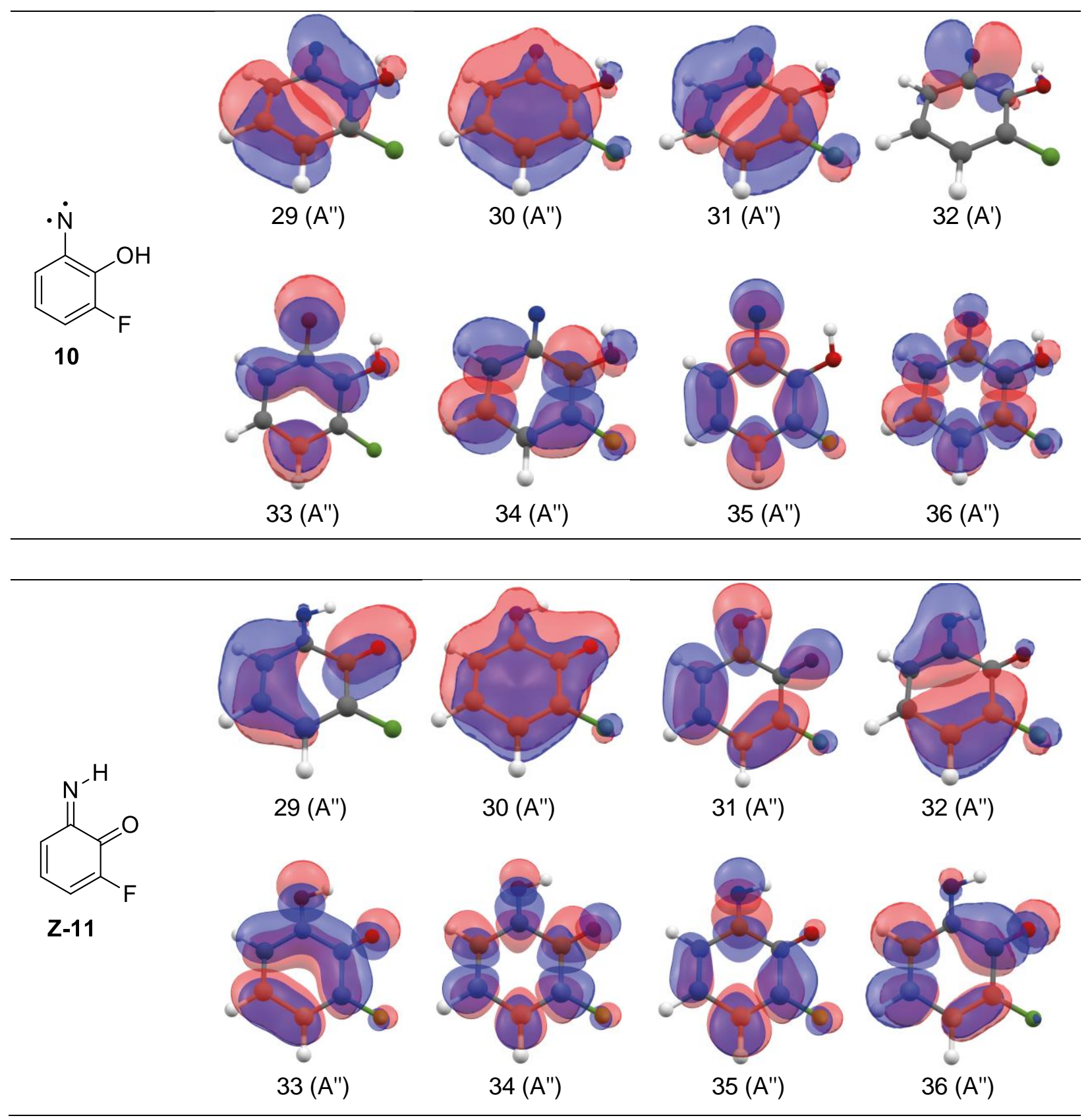

Figure S6. Active space orbitals used in the $\operatorname{CASSCF}(8,8)$ computations for nitrene $\mathbf{1 0}$ and imino Z-11 species. Orbital occupation of each specific state can be found in 4 - Computational Section. 


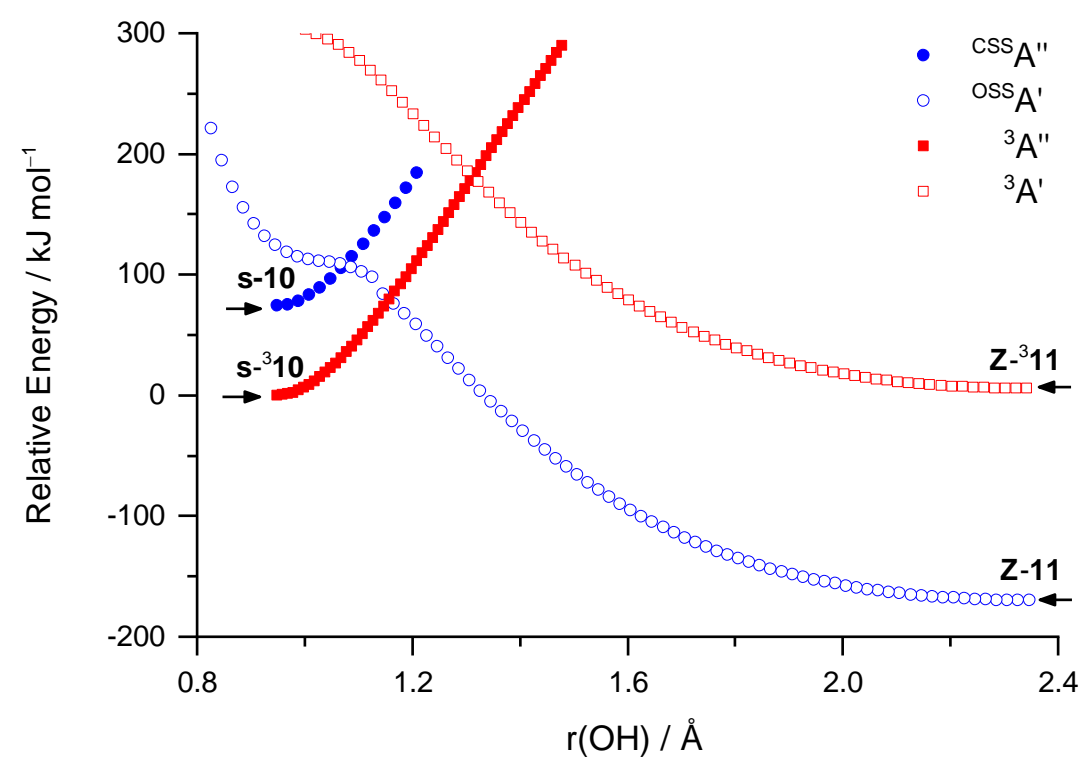

Figure S7. CASSCF $(8,8) / 6-31 \mathrm{G}(\mathrm{d})$ relaxed PES scans as a function of the $\mathrm{OH}$ distance for nitrene 10 and imino Z-11, considering the difference in the multiplicity [singlet (OSS and CSS) shown by blue circles and triplet by red squares] and symmetry [A' symmetry shown in open shape and A" in closed shape]. The arrows indicate the starting point and direction of the scans.

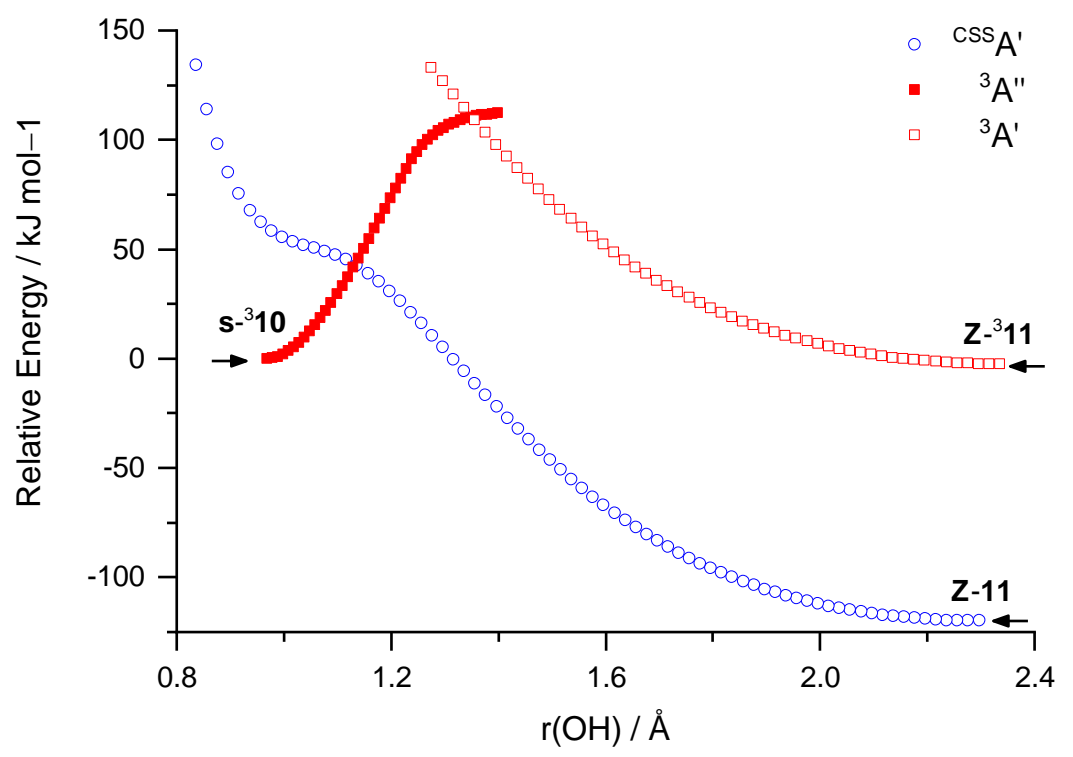

Figure S8. B3LYP/6-311+G(2d,p) relaxed PES scans as a function of the $\mathrm{OH}$ distance computed for nitrene 10 and imino Z-11, considering the difference in multiplicity [closed-shell singlet (CSS) shown in blue circles and triplet in red squares] and symmetry [A' symmetry shown in open shape and A" in closed shape]. The arrows indicate the starting point and direction of the scans. 


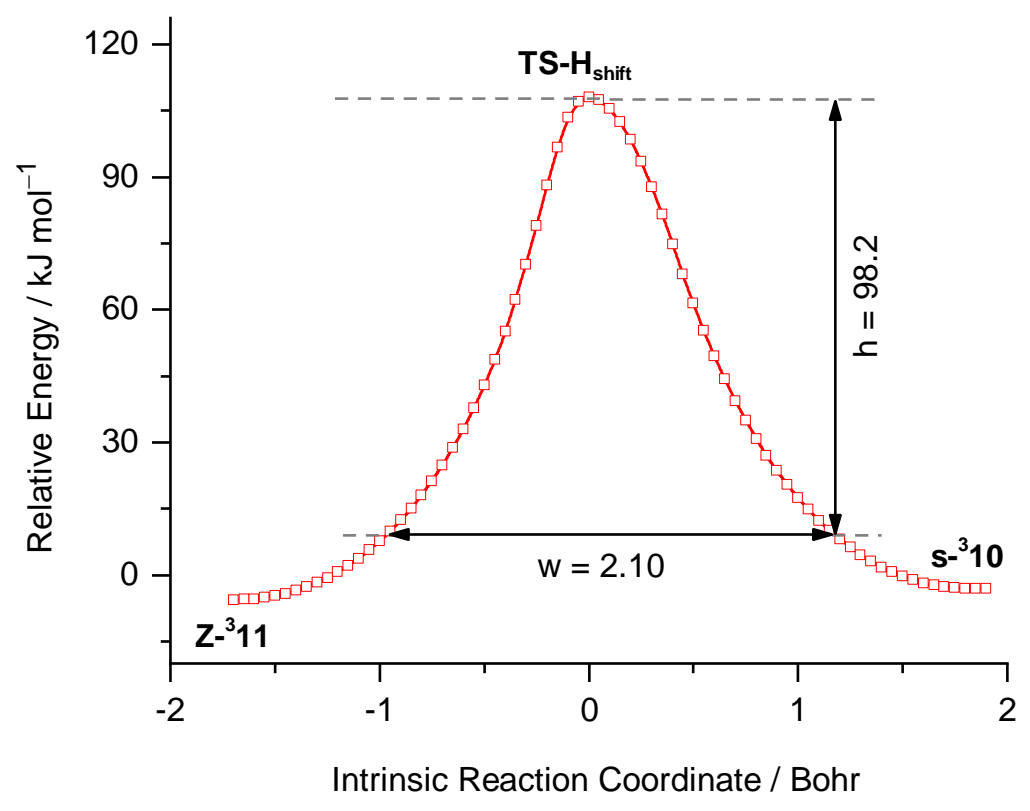

Figure S9. B3LYP/6-311+G(2d,p) intrinsic reaction coordinate (IRC) profile for the $\mathrm{H}$-shift of $\mathbf{s}^{-} \mathbf{1 0}$ to $\mathbf{Z}-{ }^{3} \mathbf{1 1}$. The relative electronic energy is given in relation to the energy of s- ${ }^{3} \mathbf{1 0}$. The vertical arrow establishes the zero-point corrected energy of the reactant $\mathbf{s}^{3}{ }^{3} \mathbf{1 0}$ relative to the transitionstate $\left(\mathrm{h}=98.2 \mathrm{~kJ} \mathrm{~mol}^{-1}\right)$. The horizontal arrow establishes the barrier width considering the zeropoint corrected energy values of the stationary points superimposed with the pure electronic IRC energy profile $(\mathrm{w}=2.10 \mathrm{Bohr})$. 

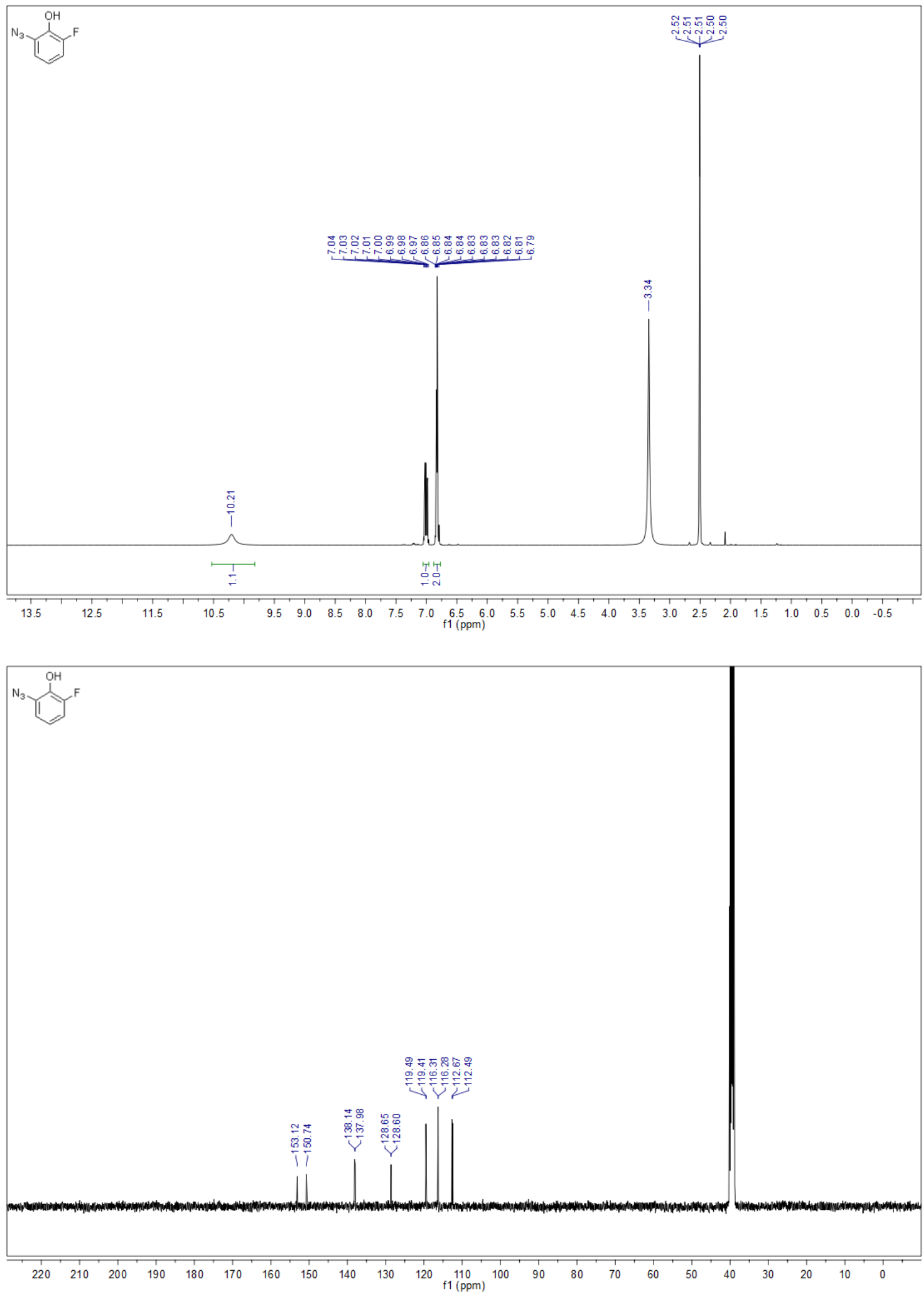

Figure S10. ${ }^{1} \mathrm{H}$ (top) and ${ }^{13} \mathrm{C}$ (bottom) NMR spectra of 3-fluoro-2-hydroxyphenylazide (9) in DMSO- $\mathrm{d}_{6}$. 


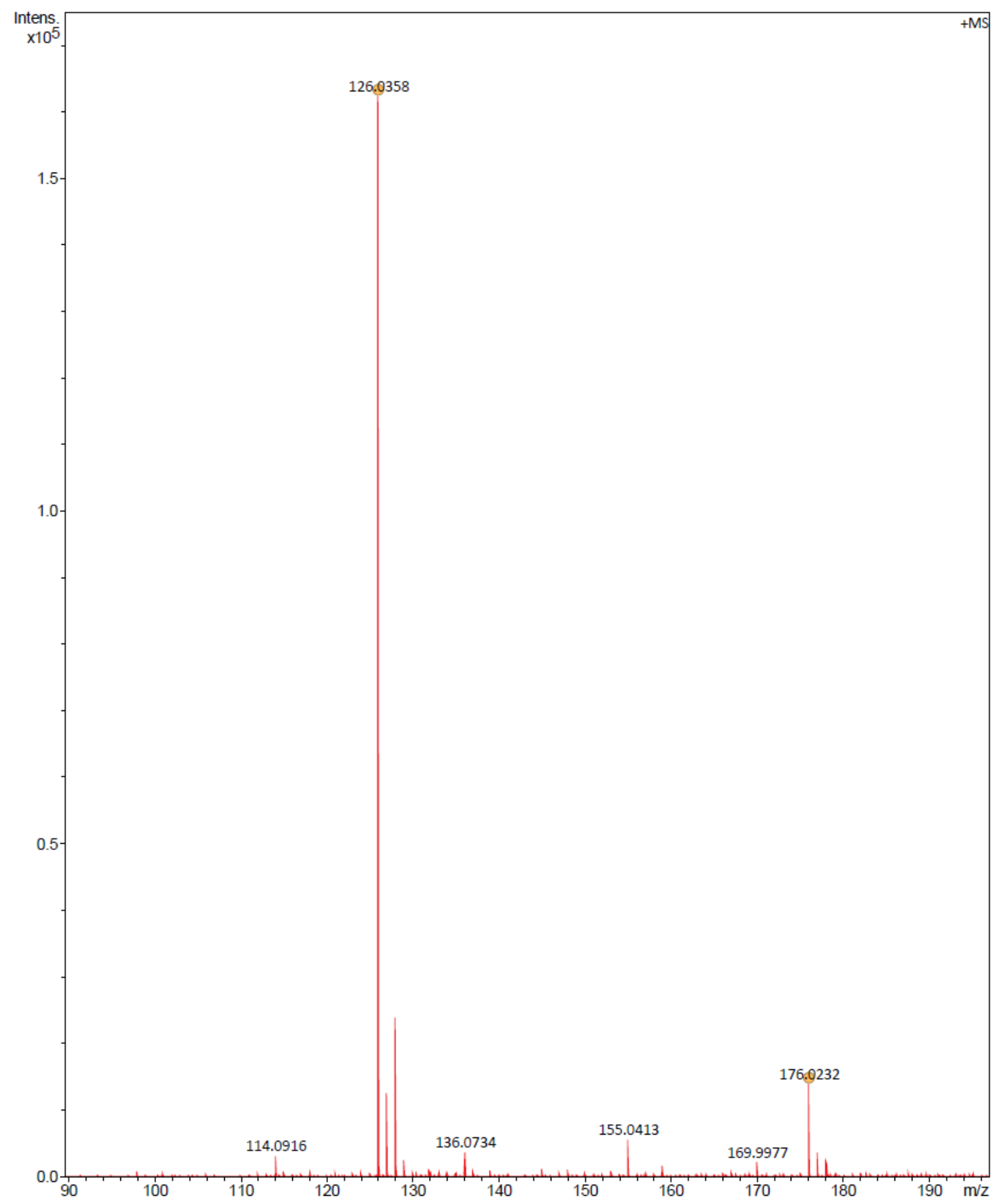

Figure S11. Electrospray ionization mass spectrum in positive-ion mode $\left(\mathrm{HRMS}-\mathrm{ESI}^{+}\right)$of 3-fluoro-2-hydroxyphenylazide (9). 


\section{Tables}

Table S1. Relative Gibbs energy at $298 \mathrm{~K}\left(\Delta G_{298 \mathrm{~K}}\right.$ in $\left.\mathrm{kJ} \mathrm{mol}^{-1}\right)$ computed at the B3LYP/6-311+G(2d,p) and CBS-QB3 levels of theory for conformers of 2-hydroxyphenylazide 9' and 3-fluoro-2-hydroxyphenylazide 9 and their equilibrium populations at $298 \mathrm{~K}$ (Pop $298 \mathrm{~K}$ in \%). ${ }^{\mathrm{a}}$

\begin{tabular}{|c|c|c|c|}
\hline $\begin{array}{l}\text { Structures } \\
9^{\prime}, 9 \\
\mathrm{R}=\mathrm{H}, \mathrm{F}\end{array}$ & $\bar{N}_{i}^{+}$ & & $N=\stackrel{+}{N}=\bar{N}$ \\
\hline Name & as-9' | as-9 & aa-9' | aa-9 & \begin{tabular}{l|l} 
sa-9' | sa-9 & sal
\end{tabular} \\
\hline$\Delta G_{298 \mathrm{~K}}(\mathrm{~B} 3 \mathrm{LYP})$ & $0.0 \mid 0.0$ & $14.8 \mid 3.5$ & $10.6 \mid 0.8$ \\
\hline$\Delta G_{298 \mathrm{~K}}(\mathrm{CBS}-\mathrm{QB} 3)$ & $0.0 \mid 0.0$ & $15.5 \mid 4.5$ & $12.8 \mid 2.6$ \\
\hline Pop $_{298 \mathrm{~K}}$ & 99.2 | 66.1 & $0.2 \mid 10.7$ & $0.6 \mid 23.1$ \\
\hline
\end{tabular}

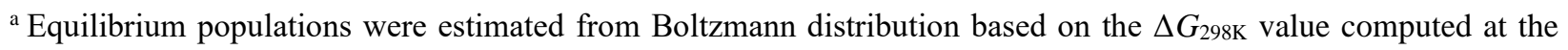
CBS-QB3 level of theory. In the names of structures, a stands for anti and s stands for syn, which corresponds to the orientation of the azido (first letter) and hydroxy (second letter) moieties, relative to one another. 
Table S2. Definition of internal coordinates used in the normal mode analysis of a- ${ }^{3} \mathbf{1 0}{ }^{a}$

\begin{tabular}{|c|c|c|}
\hline Coordinate & Definition & $\begin{array}{c}\text { Approximate } \\
\text { description }\end{array}$ \\
\hline $\mathrm{S}_{1}$ & $\mathrm{r}_{8,13}$ & $v(\mathrm{OH})$ \\
\hline $\mathrm{S}_{2}$ & $\left(3^{-1 / 2}\right)\left(r_{6,12}+r_{5,11}+r_{4,10}\right)$ & $v_{a}(\mathrm{CH})$ \\
\hline $\mathrm{S}_{3}$ & $\left(2^{-1 / 2}\right)\left(\mathrm{r}_{6,12}-\mathrm{r}_{4,10}\right)$ & $v_{b}(\mathrm{CH})$ \\
\hline $\mathrm{S}_{4}$ & $\left(6^{-1 / 2}\right)\left(-r_{6,12}+2 r_{5,11}-r_{4,10}\right)$ & $v_{c}(\mathrm{CH})$ \\
\hline $\mathrm{S}_{5}$ & $\left(12^{-1 / 2}\right)\left(2 r_{3,4}-r_{4,5}-r_{5,6}+2 r_{6,1}-r_{1,2}-r_{2,3}\right)$ & $v_{a}(C C)$ \\
\hline $\mathrm{S}_{6}$ & $\left(4^{-1 / 2}\right)\left(r_{4,5}-r_{5,6}+r_{1,2}-r_{2,3}\right)$ & $v_{\mathrm{b}}(\mathrm{CC})$ \\
\hline $\mathrm{S}_{7}$ & $\left(4^{-1 / 2}\right)\left(r_{4,5}+r_{5,6}-r_{1,2}-r_{2,3}\right)$ & $v_{c}(C C)$ \\
\hline $\mathrm{S}_{8}$ & $\left(12^{-1 / 2}\right)\left(2 r_{3,4}-r_{4,5}+r_{5,6}-2 r_{6,1}+r_{1,2}-r_{2,3}\right)$ & $v_{\mathrm{d}}(\mathrm{CC})$ \\
\hline $\mathrm{S}_{9}$ & $\left(6^{-1 / 2}\right)\left(r_{3,4}-r_{4,5}+r_{5,6}-r_{6,1}+r_{1,2}-r_{2,3}\right)$ & $v_{\mathrm{e}}(\mathrm{CC})$ \\
\hline $\mathrm{S}_{10}$ & $\left(6^{-1 / 2}\right)\left(r_{3,4}+r_{4,5}+r_{5,6}+r_{6,1}+r_{1,2}+r_{2,3}\right)$ & $v_{\mathrm{f}}(\mathrm{CC})$ \\
\hline$S_{11}$ & $\mathrm{r}_{1,7}$ & $v(\mathrm{C}-\mathrm{N})$ \\
\hline $\mathrm{S}_{12}$ & $\mathrm{r}_{2,8}$ & $v(\mathrm{C}-\mathrm{O})$ \\
\hline $\mathrm{S}_{13}$ & $\mathrm{r}_{3,9}$ & $v(\mathrm{C}-\mathrm{F})$ \\
\hline $\mathrm{S}_{14}$ & $\left(6^{-1 / 2}\right)\left(\beta_{1,12,6}-\beta_{5,12,6}+\beta_{6,11,5}-\beta_{4,11,5}+\beta_{5,10,4}-\beta_{3,10,4}\right)$ & $\delta_{\mathrm{a}}(\mathrm{CH})$ \\
\hline $\mathrm{S}_{15}$ & $\left(4^{-1 / 2}\right)\left(\beta_{1,12,6}-\beta_{5,12,6}-\beta_{5,10,4}+\beta_{3,10,4}\right)$ & $\delta_{\mathrm{b}}(\mathrm{CH})$ \\
\hline$S_{16}$ & $\left(12^{-1 / 2}\right)\left(-\beta_{1,12,6}+\beta_{5,12,6}+2 \beta_{6,11,5}-2 \beta_{4,11,5}-\beta_{5,10,4}+\beta_{3,10,4}\right)$ & $\delta_{\mathrm{c}}(\mathrm{CH})$ \\
\hline$S_{17}$ & $\left(2^{-1 / 2}\right)\left(\beta_{6,7,1}-\beta_{2,7,1}\right)$ & $\delta(\mathrm{C}-\mathrm{N})$ \\
\hline $\mathrm{S}_{18}$ & $\left(2^{-1 / 2}\right)\left(\beta_{4,9,3}-\beta_{2,9,3}\right)$ & $\delta(\mathrm{C}-\mathrm{F})$ \\
\hline $\mathrm{S}_{19}$ & $\left(2^{-1 / 2}\right)\left(\beta_{1,8,2}-\beta_{3,8,2}\right)$ & $\delta(\mathrm{C}-\mathrm{O})$ \\
\hline $\mathrm{S}_{20}$ & $\beta_{2,13,8}$ & $\delta(\mathrm{OH})$ \\
\hline $\mathrm{S}_{21}$ & $\left(6^{-1 / 2}\right)\left(\beta_{3,1,2}-\beta_{2,6,1}+\beta_{1,5,6}-\beta_{6,4,5}+\beta_{5,3,4}-\beta_{4,2,3}\right)$ & $\delta_{\mathrm{a}}($ ring $)$ \\
\hline $\mathrm{S}_{22}$ & $\left(12^{-1 / 2}\right)\left(2 \beta_{3,1,2}-\beta_{2,6,1}-\beta_{1,5,6}+2 \beta_{6,4,5}-\beta_{5,3,4}-\beta_{4,2,3}\right)$ & $\delta_{\mathrm{b}}($ ring $)$ \\
\hline $\mathrm{S}_{23}$ & $\left(4^{-1 / 2}\right)\left(\beta_{2,6,1}-\beta_{1,5,6}+\beta_{5,3,4}-\beta_{4,2,3}\right)$ & $\delta_{\mathrm{c}}($ ring $)$ \\
\hline $\mathrm{S}_{24}$ & $\left(6^{-1 / 2}\right)\left(\tau_{3,2,1,6}-\tau_{2,1,6,5}+\tau_{1,6,5,4}-\tau_{6,5,4,3}+\tau_{5,4,3,2}-\tau_{4,3,2,1}\right)$ & $\tau_{\mathrm{a}}$ (ring) \\
\hline $\mathrm{S}_{25}$ & $\left(12^{-1 / 2}\right)\left(-\tau_{32,1,6}+2 \tau_{2,1,6,5}-\tau_{1,6,5,4}-\tau_{6,5,4,3}+2 \tau_{5,4,3,2}-\tau_{4,3,2,1}\right)$ & $\tau_{b}($ ring $)$ \\
\hline $\mathrm{S}_{26}$ & $\left(4^{-1 / 2}\right)\left(\tau_{3,2,1,6}-\tau_{1,6,5,4}+\tau_{6,5,4,3}-\tau_{4,3,2,1}\right)$ & $\tau_{c}$ (ring) \\
\hline$S_{27}$ & $\left(2^{-1 / 2}\right)\left(\tau_{13,8,2,1}-\tau_{13,8,2,3}\right)$ & $\tau(\mathrm{OH})$ \\
\hline $\mathrm{S}_{28}$ & $\gamma_{7,2,1,6}$ & $\gamma(\mathrm{C}-\mathrm{N})$ \\
\hline $\mathrm{S}_{29}$ & $\gamma_{8,3,2,2,1}$ & $\gamma(\mathrm{C}-\mathrm{O})$ \\
\hline $\mathrm{S}_{30}$ & $\gamma_{9,4,3,2}$ & $\gamma(\mathrm{C}-\mathrm{F})$ \\
\hline $\mathrm{S}_{31}$ & $\left(3^{-1 / 2}\right)\left(\gamma_{12,1,6,5}+\gamma_{11,6,5,4}+\gamma_{10,5,4,3}\right)$ & $\gamma_{\mathrm{a}}(\mathrm{CH})$ \\
\hline $\mathrm{S}_{32}$ & $\left(6^{-1 / 2}\right)\left(-\gamma_{12,1,6,5}+2 \gamma_{11,6,5,4}-\gamma_{10,5,4,3}\right)$ & $\gamma_{\mathrm{b}}(\mathrm{CH})$ \\
\hline $\mathrm{S}_{33}$ & $\left(2^{-1 / 2}\right)\left(\gamma_{12,1,6,5}-\gamma_{10,5,4,3}\right)$ & $\gamma_{c}(\mathrm{CH})$ \\
\hline
\end{tabular}

${ }^{a}$ Abbreviations: $v=$ stretching, $\delta=$ in-plane bending, $\gamma=$ out-of-plane bending, $\tau=$ torsion, ring $=6$-member ring (benzene). See Figure $S 5$ for the atom numbering scheme; $r_{i, j}$ is the distance between atoms $A_{i}$ and $A_{j} ; \beta_{i, j, k}$ is the angle between vectors $A_{k} A_{i}$ and $A_{k} A_{j} ; \tau_{i, j, k, l}$ is the dihedral angle between the plane defined by $A_{i}, A_{j}, A_{k}$ and the plane defined by $A_{j}, A_{k}$ and $A_{l}$ atoms; $\gamma_{i, j, k, l}$ is the angle between the vector $A_{k} A_{i}$ and the plane defined by atoms $A_{j}, A_{k}, A_{l}$. The combinations $[(+),(+)]$ and $[(+),(-)]$ denote in-phase and in-opposite-phase couplings between coordinates of different types. 
Table S3. Definition of internal coordinates used in the normal mode analysis of Z-11. ${ }^{a}$

\begin{tabular}{|c|c|c|}
\hline Coordinate & Definition & $\begin{array}{c}\text { Approximate } \\
\text { description }\end{array}$ \\
\hline $\mathrm{S}_{1}$ & $\mathbf{r}_{7,13}$ & $v(\mathrm{NH})$ \\
\hline $\mathrm{S}_{2}$ & $\left(3^{-1 / 2}\right)\left(r_{6,12}+r_{5,11}+r_{4,10}\right)$ & $v_{\mathrm{a}}(\mathrm{CH})$ \\
\hline $\mathrm{S}_{3}$ & $\left(2^{-1 / 2}\right)\left(r_{6,12}-r_{4,10}\right)$ & $v_{b}(\mathrm{CH})$ \\
\hline $\mathrm{S}_{4}$ & $\left(6^{-1 / 2}\right)\left(-r_{6,12}+2 r_{5,11}-r_{4,10}\right)$ & $v_{c}(\mathrm{CH})$ \\
\hline $\mathrm{S}_{5}$ & $\mathrm{r}_{2,8}$ & $v(\mathrm{C}=\mathrm{O})$ \\
\hline $\mathrm{S}_{6}$ & $r_{1,7}$ & $v(\mathrm{C}=\mathrm{N})$ \\
\hline $\mathrm{S}_{7}$ & $\left(2^{-1 / 2}\right)\left(r_{4,3}-r_{6,5}\right)$ & $v(\mathrm{C}=\mathrm{C})_{\mathrm{as}}$ \\
\hline $\mathrm{S}_{8}$ & $\left(2^{-1 / 2}\right)\left(r_{4,3}+r_{6,5}\right)$ & $v(\mathrm{C}=\mathrm{C})_{\mathrm{s}}$ \\
\hline $\mathrm{S}_{9}$ & $\left(2^{-1 / 2}\right)\left(r_{2,3}-r_{4,5}\right)$ & $v_{\mathrm{a}}(\mathrm{C}-\mathrm{C})_{\mathrm{as}}$ \\
\hline $\mathrm{S}_{10}$ & $\left(2^{-1 / 2}\right)\left(r_{2,3}+r_{4,5}\right)$ & $v_{\mathrm{a}}(\mathrm{C}-\mathrm{C})_{\mathrm{s}}$ \\
\hline$S_{11}$ & $\left(2^{-1 / 2}\right)\left(r_{2,1}-r_{1,6}\right)$ & $v_{\mathrm{b}}(\mathrm{C}-\mathrm{C})_{\mathrm{as}}$ \\
\hline$S_{12}$ & $\left(2^{-1 / 2}\right)\left(r_{2,1}+r_{1,6}\right)$ & $v_{b}(C-C)_{s}$ \\
\hline$S_{13}$ & $\mathrm{r}_{3,9}$ & $v(\mathrm{C}-\mathrm{F})$ \\
\hline $\mathrm{S}_{14}$ & $\left(6^{-1 / 2}\right)\left(\beta_{1,12,6}-\beta_{5,12,6}+\beta_{6,11,5}-\beta_{4,11,5}+\beta_{5,10,4}-\beta_{3,10,4}\right)$ & $\delta_{\mathrm{a}}(\mathrm{CH})$ \\
\hline $\mathrm{S}_{15}$ & $\left(4^{-1 / 2}\right)\left(\beta_{1,12,6}-\beta_{5,12,6}-\beta_{5,10,4}+\beta_{3,10,4}\right)$ & $\delta_{b}(\mathrm{CH})$ \\
\hline $\mathrm{S}_{16}$ & $\left(12^{-1 / 2}\right)\left(-\beta_{1,12,6}+\beta_{5,12,6}+2 \beta_{6,11,5}-2 \beta_{4,11,5}-\beta_{5,10,4}+\beta_{3,10,4}\right)$ & $\delta_{\mathrm{c}}(\mathrm{CH})$ \\
\hline $\mathrm{S}_{17}$ & $\left(2^{-1 / 2}\right)\left(\beta_{6,7,1}-\beta_{2,7,1}\right)$ & $\delta(\mathrm{C}=\mathrm{N})$ \\
\hline $\mathrm{S}_{18}$ & $\left(2^{-1 / 2}\right)\left(\beta_{4,9,3}-\beta_{2,9,3}\right)$ & $\delta(\mathrm{C}-\mathrm{F})$ \\
\hline $\mathrm{S}_{19}$ & $\left(2^{-1 / 2}\right)\left(\beta_{1,8,2}-\beta_{3,8,2}\right)$ & $\delta(\mathrm{C}=\mathrm{O})$ \\
\hline $\mathrm{S}_{20}$ & $\beta_{1,13,7}$ & $\delta(\mathrm{NH})$ \\
\hline $\mathrm{S}_{21}$ & $\left(6^{-1 / 2}\right)\left(\beta_{3,1,2}-\beta_{2,6,1}+\beta_{1,5,6}-\beta_{6,4,5}+\beta_{5,3,4}-\beta_{4,2,3}\right)$ & $\delta_{\mathrm{a}}($ (ring) \\
\hline $\mathrm{S}_{22}$ & $\left(12^{-1 / 2}\right)\left(2 \beta_{3,1,2}-\beta_{2,6,1}-\beta_{1,5,6}+2 \beta_{6,4,5}-\beta_{5,3,4}-\beta_{4,2,3}\right)$ & $\delta_{\mathrm{b}}($ ring $)$ \\
\hline$S_{23}$ & $\left(4^{-1 / 2}\right)\left(\beta_{2,6,1}-\beta_{1,5,6}+\beta_{5,3,4}-\beta_{4,2,3}\right)$ & $\delta_{\mathrm{c}}($ ring $)$ \\
\hline $\mathrm{S}_{24}$ & $\left(6^{-1 / 2}\right)\left(\tau_{3,2,1,6}-\tau_{2,1,6,5}+\tau_{1,6,5,4}-\tau_{6,5,4,3}+\tau_{5,4,3,2}-\tau_{4,3,2,1}\right)$ & $\tau_{\mathrm{a}}$ (ring) \\
\hline $\mathrm{S}_{25}$ & $\left(12^{-1 / 2}\right)\left(-\tau_{32,1,6}+2 \tau_{2,1,6,5}-\tau_{1,6,5,4}-\tau_{6,5,4,3}+2 \tau_{5,4,3,2}-\tau_{4,3,2,1}\right)$ & $\tau_{\mathrm{b}}$ (ring) \\
\hline $\mathrm{S}_{26}$ & $\left(4^{-1 / 2}\right)\left(\tau_{3,2,1,6}-\tau_{1,6,5,4}+\tau_{6,5,4,3}-\tau_{4,3,2,1}\right)$ & $\tau_{c}($ ring $)$ \\
\hline $\mathrm{S}_{27}$ & $\left(2^{-1 / 2}\right)\left(\tau_{13,7,1,2}-\tau_{13,7,1,6}\right)$ & $\tau(\mathrm{NH})$ \\
\hline $\mathrm{S}_{28}$ & $\gamma_{7,2,1,6}$ & $\gamma(\mathrm{C}=\mathrm{N})$ \\
\hline $\mathrm{S}_{29}$ & $\gamma_{8,3,2,1}$ & $\gamma(\mathrm{C}=\mathrm{O})$ \\
\hline $\mathrm{S}_{30}$ & $\gamma_{9,4,3,2}$ & $\gamma(\mathrm{C}-\mathrm{F})$ \\
\hline$S_{31}$ & $\left(3^{-1 / 2}\right)\left(\gamma_{12,1,6,5}+\gamma_{11,6,5,4}+\gamma_{10,5,4,3}\right)$ & $\gamma_{\mathrm{a}}(\mathrm{CH})$ \\
\hline $\mathrm{S}_{32}$ & $\left(6^{-1 / 2}\right)\left(-\gamma_{12,1,6,5}+2 \gamma_{11,6,5,4}-\gamma_{10,5,4,3}\right)$ & $\gamma_{b}(\mathrm{CH})$ \\
\hline $\mathrm{S}_{33}$ & $\left(2^{-1 / 2}\right)\left(\gamma_{12,1,6,5}-\gamma_{10,5,4,3}\right)$ & $\gamma_{\mathrm{c}}(\mathrm{CH})$ \\
\hline
\end{tabular}

${ }^{a}$ Abbreviations: $v=$ stretching, $\delta=$ in-plane bending, $\gamma=$ out-of-plane bending, $\tau=$ torsion, ring $=$ six-membered ring. See Figure S5 for the atom numbering scheme; $r_{i, j}$ is the distance between atoms $A_{i}$ and $A_{j}$; $\beta_{i, j, k}$ is the angle between vectors $A_{k} A_{i}$ and $A_{k} A_{j} ; \tau_{i, j, k, l}$ is the dihedral angle between the plane defined by $A_{i}, A_{j}, A_{k}$ and the plane defined by $A_{j}$, $A_{k}$ and $A_{l}$ atoms; $\gamma_{i, j, k, l}$ is the angle between the vector $A_{k} A_{i}$ and the plane defined by atoms $A_{j}, A_{k}, A_{l}$. The combinations $[(+),(+)]$ and $[(+),(-)]$ denote in-phase and in-opposite-phase couplings between coordinates of different types. 
Table S4. Experimental IR spectral data (nitrogen matrix at $10 \mathrm{~K}$ ), B3LYP/6-311+G(2d,p) computed vibrational frequencies $\left(\tilde{v}, \mathrm{~cm}^{-1}\right)$ and infrared intensities $\left(A^{\text {th }}, \mathrm{km} \mathrm{mol}^{-1}\right)$, and vibrational assignment of triplet anti-3-fluoro-2-hydroxyphenylnitrene $\mathbf{a}^{3}{ }^{3} \mathbf{1 0}$.

\begin{tabular}{|c|c|c|c|c|}
\hline \multicolumn{2}{|c|}{ Experimental $^{a}$} & \multicolumn{2}{|c|}{ Computed $^{b}$} & \multirow{2}{*}{$\mathrm{PED}^{c}$} \\
\hline$\tilde{v}$ & I & $\tilde{v}$ & $A^{\text {th }}$ & \\
\hline 3576 & $\mathrm{br}$ & 3596 & 130.2 & $100.0[v(\mathrm{OH})]$ \\
\hline 1571 & $\mathrm{~s}$ & 1564 & 55.8 & $35.2\left[v_{b}(C C)\right] ; 29.4\left[v_{a}(C C)\right]$ \\
\hline 1538 & $\mathrm{~s}$ & 1536 & 75.9 & $21.8\left[v_{b}(C C)\right] ; 20.1\left[v_{a}(C C)\right]: 17.2\left[\delta_{b}(C H)\right]$ \\
\hline \multirow[t]{2}{*}{1444} & vs & 1433 & 141.8 & $26.0\left[\delta_{\mathrm{a}}(\mathrm{CH})\right] ; 17.6[v(\mathrm{C}-\mathrm{O})] ; 12.3\left[v_{\mathrm{e}}(\mathrm{CC})\right] ; 10.1\left[\mathrm{v}_{\mathrm{a}}(\mathrm{CC})\right]$ \\
\hline & & 1420 & 8.4 & $20.9\left[v_{\mathrm{c}}(\mathrm{CC})\right] ; 20.9\left[\delta_{\mathrm{b}}(\mathrm{CH})\right] ; 17.4\left[\delta_{\mathrm{a}}(\mathrm{CH})\right] \quad 14.6[\delta(\mathrm{OH})]$ \\
\hline 1339 & $\mathrm{~m}$ & 1344 & 37.2 & $40.5\left[v_{\mathrm{e}}(\mathrm{CC})\right]+34.4[\delta(\mathrm{OH})]$ \\
\hline 1303 & $\mathrm{w}$ & 1298 & 26.5 & $50.7[v(\mathrm{C}-\mathrm{N})] ; 16.7\left[\delta_{\mathrm{a}}(\right.$ ring $\left.)\right] ; 10.2[v(\mathrm{C}-\mathrm{O})]$ \\
\hline 1249 & w & 1244 & 79.5 & $29.7\left[\delta_{\mathrm{a}}(\mathrm{CH})\right] ; 12.6\left[\mathrm{v}_{\mathrm{d}}(\mathrm{CC})\right] ; 12.6\left[\mathrm{v}_{\mathrm{f}}(\mathrm{CC})\right] ; 12.2[\mathrm{v}(\mathrm{C}-\mathrm{F})]$ \\
\hline 1230 & $\mathrm{~m}$ & 1220 & 64.7 & $53.6\left[v_{\mathrm{e}}(\mathrm{CC})\right]-26.1[\delta(\mathrm{OH})]$ \\
\hline $1191 / 1187$ & $\mathrm{w}$ & 1175 & 24.3 & $18.3[v(\mathrm{C}-\mathrm{O})] ; 16.6\left[v_{\mathrm{d}}(\mathrm{CC})\right] ; 16.3[v(\mathrm{C}-\mathrm{F})] ; 14.1\left[v_{\mathrm{a}}(\mathrm{CC})\right] ; 11.4[v(\mathrm{C}-\mathrm{N})]$ \\
\hline 1144 & $\mathrm{w}$ & 1139 & 20.8 & $59.9\left[\delta_{c}(\mathrm{CH})\right] ; 18.9\left[v_{b}(\mathrm{CC})\right]$ \\
\hline 1056 & $\mathrm{w}$ & 1051 & 15.0 & $35.6\left[v_{\mathrm{c}}(\mathrm{CC})\right] ; 29.4\left[\delta_{\mathrm{b}}(\mathrm{CH})\right] ; 16.6\left[v_{\mathrm{f}}(\mathrm{CC})\right]$ \\
\hline \multirow[t]{4}{*}{ 996/990 } & $\mathrm{s}$ & 978 & 103.1 & $25.2[v(\mathrm{C}-\mathrm{F})] ; 24.0\left[v_{\mathrm{d}}(\mathrm{CC})\right]$ \\
\hline & & 938 & 0.2 & $116.0\left[\gamma_{\mathrm{b}}(\mathrm{CH})\right]$ \\
\hline & & 851 & 0.1 & $99.5\left[\gamma_{c}(\mathrm{CH})\right]$ \\
\hline & & 823 & 7.8 & $49.8\left[\delta_{\mathrm{a}}(\right.$ ring $\left.)\right] ; 15.7[v(\mathrm{C}-\mathrm{O})] ; 12.3\left[\delta_{\mathrm{b}}(\mathrm{ring})\right]$ \\
\hline $768 / 765$ & $\mathrm{~m}$ & 754 & 47.1 & $67.5\left[\gamma_{\mathrm{a}}(\mathrm{CH})\right] ; 13.9[\gamma(\mathrm{C}-\mathrm{N})] \quad 11.5[\gamma(\mathrm{C}-\mathrm{F})]$ \\
\hline 696 & $\mathrm{w}$ & 686 & 17.6 & $52.6\left[v_{f}(C C)\right] ; 13.1[v(C-F)]$ \\
\hline 693 & $\mathrm{w}$ & 681 & 21.7 & $30.4\left[\tau_{\mathrm{a}}\right.$ (ring) $] ; 30.1\left[\gamma_{\mathrm{a}}(\mathrm{CH})\right] ; 29.6[\gamma(\mathrm{C}-\mathrm{O})] ; 13.2[\gamma(\mathrm{C}-\mathrm{N})]$ \\
\hline
\end{tabular}

${ }^{\text {a }}$ Experimental intensities $(\mathrm{I})$ are given in qualitative terms: $\mathrm{vs}=$ very strong $\mathrm{s}=$ strong; $\mathrm{m}=$ medium; $\mathrm{w}=\mathrm{weak}$; br = broad. The IR spectrum reported corresponds to the region between 1750 and $600 \mathrm{~cm}^{-1}$ and the $v(\mathrm{OH})$ mode. ${ }^{b}$ Computed harmonic wavenumbers $\left(\mathrm{cm}^{-1}\right)$ were multiplied by a 0.979 factor, except the $v(\mathrm{OH})$ mode which was multiplied by a 0.950 factor. ${ }^{c}$ Abbreviations: $v=$ stretching, $\delta=$ in-plane bending, $\gamma=$ out-of-plane bending, $\tau=$ torsion, ring $=$ six-membered ring (benzene). PEDs are expressed in \%, and the PED matrices lower than $10 \%$ are not included. Definition of internal coordinates is given in Table S2. 
Table S5. Experimental IR spectral data (nitrogen matrix at $10 \mathrm{~K})$, B3LYP/6-311+G(2d,p) computed vibrational frequencies $\left(\tilde{v}, \mathrm{~cm}^{-1}\right)$ and infrared intensities $\left(A^{\text {th }}, \mathrm{km} \mathrm{mol}^{-1}\right)$, and vibrational assignment of (Z)-2-fluoro-6-iminocyclohexa-2,4-dienone Z-11.

\begin{tabular}{|c|c|c|c|c|}
\hline \multicolumn{2}{|c|}{ Experimental $^{a}$} & \multicolumn{2}{|c|}{ Calculated $^{b}$} & \multirow{2}{*}{$\mathrm{PED}^{c}$} \\
\hline$\tilde{v}$ & $\mathrm{I}$ & $\tilde{v}$ & $A^{\text {th }}$ & \\
\hline 3216 & br & 3218 & 14 & $99.9[\mathrm{v}(\mathrm{NH})]$ \\
\hline 1691 & $\mathrm{~s}$ & 1701 & 170.3 & $81.3[v(\mathrm{C}=\mathrm{O})]$ \\
\hline \multirow[t]{2}{*}{1648} & s & 1659 & 53.3 & $62.5\left[v(\mathrm{C}=\mathrm{C})_{\mathrm{as}}\right] ; 10.2\left[\delta_{\mathrm{b}}(\mathrm{CH})\right]$ \\
\hline & & 1604 & 38.9 & $75.5[v(\mathrm{C}=\mathrm{N})]$ \\
\hline 1576 & w & 1576 & 8.9 & $69.3\left[v(\mathrm{C}=\mathrm{C})_{\mathrm{s}}\right]$ \\
\hline $1417 / 1407$ & $\mathrm{w}$ & 1410 & 5.9 & $21.0\left[\delta_{\mathrm{a}}(\mathrm{CH})\right] ; 14.8\left[\mathrm{v}_{\mathrm{b}}(\mathrm{C}-\mathrm{C})_{\mathrm{as}}\right] ; 14.4\left[\delta_{\mathrm{b}}(\mathrm{CH})\right] ; 12.9\left[\delta_{\mathrm{c}}(\mathrm{CH})\right] ; 11.7[\delta(\mathrm{NH})]$ \\
\hline 1358 & $\mathrm{~m}$ & 1347 & 30.0 & $46.9[\delta(\mathrm{NH})] ; 20.8\left[\delta_{\mathrm{b}}(\mathrm{CH})\right]$ \\
\hline 1347 & $\mathrm{~m}$ & 1340 & 61.7 & $39.5\left[\delta_{\mathrm{a}}(\mathrm{CH})\right] ; 13.2\left[v_{\mathrm{a}}(\mathrm{C}-\mathrm{C})_{\mathrm{as}}\right] ; 11.9\left[v_{\mathrm{a}}(\mathrm{C}-\mathrm{C})_{\mathrm{s}}\right]$ \\
\hline 1256 & $\mathrm{~m}$ & 1241 & 67.8 & $34.3[v(\mathrm{C}-\mathrm{F})] ; 16.3\left[\delta_{\mathrm{b}}(\mathrm{CH})\right] ; 15.2\left[\delta_{\mathrm{a}}(\mathrm{CH})\right] ; 13.7\left[\mathrm{v}_{\mathrm{a}}(\mathrm{C}-\mathrm{C})_{\mathrm{s}}\right]$ \\
\hline 1164 & $\mathrm{~m}$ & 1163 & 40.9 & $57.2\left[\delta_{c}(\mathrm{CH})\right]$ \\
\hline 1114 & s & 1098 & 104.9 & $37.7\left[v_{\mathrm{b}}(\mathrm{C}-\mathrm{C})_{\mathrm{as}}\right] ; 18.8[\delta(\mathrm{NH})] ; 15.5\left[\delta_{\mathrm{c}}(\mathrm{CH})\right]$ \\
\hline 1018 & w & 1012 & 20.2 & $31.0\left[v_{\mathrm{a}}(\mathrm{C}-\mathrm{C})_{\mathrm{as}}\right] \quad 14.5\left[\delta_{\mathrm{b}}(\mathrm{CH})\right]$ \\
\hline \multirow[t]{2}{*}{993} & s & 979 & 35.5 & $21.7\left[v_{\mathrm{a}}(\mathrm{C}-\mathrm{C})_{\mathrm{s}}\right] ; 19.5[\delta(\mathrm{C}=\mathrm{O})] ; 18.2\left[\mathrm{v}_{\mathrm{b}}(\mathrm{C}-\mathrm{C})_{\mathrm{s}}\right] \quad 13.1[\mathrm{v}(\mathrm{C}-\mathrm{F})]$ \\
\hline & & 978 & 2.1 & $92.1\left[\gamma_{\mathrm{b}}(\mathrm{CH})\right] ; 14.0\left[\gamma_{\mathrm{c}}(\mathrm{CH})\right] ; 10.5[\tau(\mathrm{NH})]$ \\
\hline \multirow[t]{2}{*}{937} & $\mathrm{w}$ & 953 & 28.0 & $78.8[\tau(\mathrm{NH})] ; 16.7\left[\gamma_{\mathrm{b}}(\mathrm{CH})\right]$ \\
\hline & & 911 & 4.9 & $81.2\left[\gamma_{\mathrm{c}}(\mathrm{CH})\right] ; 12.2\left[\gamma_{\mathrm{a}}(\mathrm{CH})\right]$ \\
\hline \multirow[t]{2}{*}{836} & $\mathrm{~m}$ & 828 & 34.4 & $64.2\left[\delta_{\mathrm{a}}\right.$ (ring $]$ \\
\hline & & 823 & 3.8 & $29.3\left[\gamma_{\mathrm{a}}(\mathrm{CH})\right] ; 27.9[\gamma(\mathrm{C}=\mathrm{O})] ; 26.9[\gamma(\mathrm{C}=\mathrm{N})] ; 9.7[\gamma(\mathrm{C}-\mathrm{F})]$ \\
\hline \multirow[t]{2}{*}{727} & $\mathrm{~m}$ & 723 & 88.4 & $52.9\left[\gamma_{\mathrm{a}}(\mathrm{CH})\right] ; 19.8[\gamma(\mathrm{C}=\mathrm{O})] ; 17.2\left[\tau_{\mathrm{a}}(\right.$ ring $\left.)\right]$ \\
\hline & & 670 & 3.9 & $29.9\left[v_{b}(C-C)_{s}\right] ; 21.8\left[v_{a}(C-C)_{s}\right] ; 11.5\left[v(C=C)_{s}\right]$ \\
\hline
\end{tabular}

${ }^{a}$ Experimental intensities (I) are given in qualitative terms: $\mathrm{s}=$ strong; $\mathrm{m}=$ medium; $\mathrm{w}=$ weak; $\mathrm{br}=$ broad. The IR spectrum reported corresponds to the region between 1750 and $600 \mathrm{~cm}^{-1}$ and the $v(\mathrm{NH})$ mode. ${ }^{b}$ Computed harmonic wavenumbers $\left(\mathrm{cm}^{-1}\right)$ were multiplied by a 0.979 factor, except for the $v(\mathrm{NH})$ mode which was multiplied by a 0.950 factor. ${ }^{c}$ Abbreviations: $v=$ stretching, $\delta=$ in-plane bending, $\gamma=$ out-of-plane bending, $\tau=$ torsion, ring $=$ six-membered ring. PEDs are expressed in \%, and the PED matrices lower than $10 \%$ are not included. Definition of internal coordinates is given in Table S3. 


\section{Computational Section}

Optimized geometries (Cartesian coordinates, $\AA$ ), electronic energies $\left(E, E_{h}\right)$ and zero-point vibrational energy (ZPVE, $\mathrm{E}_{\mathrm{h}}$ ) computed at the B3LYP/6-311+G(2d,p), CBS-QB3 and $\operatorname{CASSCF}(8,8) / 6-31 \mathrm{G}(\mathrm{d})$ levels of theory.

as-9'

$\operatorname{B} 3 \operatorname{LYP}(E=-471.205545 ; \mathrm{ZPVE}=0.107459)$

$\begin{array}{lrrr}\mathrm{C} & 0.876096 & 0.944931 & 0.000006 \\ \mathrm{C} & -0.199146 & 0.044211 & 0.000032 \\ \mathrm{C} & 0.035767 & -1.328335 & 0.000032 \\ \mathrm{C} & 1.339474 & -1.808128 & 0.000002 \\ \mathrm{C} & 2.406391 & -0.913722 & -0.000024 \\ \mathrm{C} & 2.177104 & 0.456687 & -0.000022 \\ \mathrm{O} & 0.672545 & 2.288987 & 0.000008 \\ \mathrm{H} & -0.281055 & 2.456711 & 0.000023 \\ \mathrm{~N} & -1.483298 & 0.656112 & 0.000069 \\ \mathrm{~N} & -2.485112 & -0.058578 & -0.000016 \\ \mathrm{~N} & -3.467545 & -0.616059 & -0.000082 \\ \mathrm{H} & -0.799461 & -2.019441 & 0.000055 \\ \mathrm{H} & 1.518499 & -2.875673 & 0.000002 \\ \mathrm{H} & 3.424187 & -1.283691 & -0.000046 \\ \mathrm{H} & 2.995041 & 1.166002 & -0.000043\end{array}$

CBS-QB3 $(E=-470.325318 ; \mathrm{ZPVE}=0.106642)$

$\begin{array}{rrr}-0.872245 & 0.950633 & 0.000002 \\ 0.198145 & 0.038782 & -0.000001 \\ -0.044497 & -1.334432 & 0.000001 \\ -1.353364 & -1.806896 & 0.000006 \\ -2.415937 & -0.903870 & 0.000009 \\ -2.178427 & 0.467356 & 0.000007 \\ -0.656072 & 2.290106 & 0.000001 \\ 0.299780 & 2.438893 & -0.000003 \\ 1.484145 & 0.648824 & -0.000006 \\ 2.487523 & -0.063434 & -0.000009 \\ 3.474800 & -0.619983 & -0.000011 \\ 0.788236 & -2.029457 & -0.000002 \\ -1.539291 & -2.873874 & 0.000007 \\ -3.436758 & -1.267377 & 0.000013 \\ -2.990717 & 1.183686 & 0.000010\end{array}$

aa-9'

$\operatorname{B} 3 \operatorname{LP}(E=-471.199342 ; \mathrm{ZPVE}=0.107022)$

$\begin{array}{lrrr}\mathrm{C} & 0.899628 & 0.921892 & 0.000007 \\ \mathrm{C} & -0.220214 & 0.075129 & -0.000010 \\ \mathrm{C} & -0.033114 & -1.306463 & -0.000008 \\ \mathrm{C} & 1.245460 & -1.850789 & -0.000002 \\ \mathrm{C} & 2.352087 & -1.010718 & -0.000001 \\ \mathrm{C} & 2.175582 & 0.368733 & 0.000014 \\ \mathrm{O} & 0.676141 & 2.266451 & -0.000014 \\ \mathrm{H} & 1.520616 & 2.731262 & -0.000004 \\ \mathrm{~N} & -1.487416 & 0.707021 & 0.000008 \\ \mathrm{~N} & -2.494134 & 0.000847 & 0.000008 \\ \mathrm{~N} & -3.491413 & -0.532165 & 0.000000 \\ \mathrm{H} & -0.897547 & -1.960434 & -0.000012 \\ \mathrm{H} & 1.371603 & -2.925905 & -0.000008 \\ \mathrm{H} & 3.353492 & -1.422543 & 0.000004 \\ \mathrm{H} & 3.036877 & 1.029381 & 0.000024\end{array}$

CBS-QB3 $(E=-470.319212 ;$ ZPVE $=0.106292)$

$\begin{array}{rrr}-0.898903 & 0.926762 & 0.000000 \\ 0.220847 & 0.073494 & 0.000000 \\ 0.029305 & -1.309353 & 0.000000 \\ -1.252839 & -1.851842 & 0.000000 \\ -2.358471 & -1.007591 & 0.000000 \\ -2.177963 & 0.374007 & 0.000000 \\ -0.668384 & 2.267754 & 0.000000 \\ -1.512515 & 2.730650 & 0.000000 \\ 1.489050 & 0.704134 & 0.000000 \\ 2.495506 & -0.002960 & 0.000000 \\ 3.497656 & -0.534654 & 0.000000 \\ 0.893532 & -1.964603 & 0.000000 \\ -1.381270 & -2.927304 & 0.000000 \\ -3.361784 & -1.416412 & 0.000000 \\ -3.038234 & 1.037130 & 0.000000\end{array}$




\section{sa-9',}

B3LYP $(E=-471.199578 ;$ ZPVE $=0.106834)$

$\begin{array}{lrrr}\mathrm{C} & 0.260703 & 0.820334 & -0.000003 \\ \mathrm{C} & -0.027894 & -0.553835 & -0.000005 \\ \mathrm{C} & 1.031836 & -1.461959 & -0.000002 \\ \mathrm{C} & 2.349569 & -1.027861 & 0.000004 \\ \mathrm{C} & 2.627538 & 0.334417 & 0.000007 \\ \mathrm{C} & 1.582528 & 1.250801 & 0.000003 \\ \mathrm{O} & -0.797272 & 1.688065 & -0.000009 \\ \mathrm{H} & -0.476549 & 2.596750 & -0.000001 \\ \mathrm{~N} & -1.320112 & -1.118918 & -0.000012 \\ \mathrm{~N} & -2.352830 & -0.443208 & 0.000003 \\ \mathrm{~N} & -3.395304 & -0.010403 & 0.000015 \\ \mathrm{H} & 0.792748 & -2.517861 & -0.000004 \\ \mathrm{H} & 3.154271 & -1.751900 & 0.000006 \\ \mathrm{H} & 3.650878 & 0.688059 & 0.000012 \\ \mathrm{H} & 1.788865 & 2.316746 & 0.000004\end{array}$

CBS-QB3 $(E=-470.319660 ; \mathrm{ZPVE}=0.106031)$

$\begin{array}{rrr}-0.256950 & 0.821906 & 0.000001 \\ 0.027017 & -0.557375 & 0.000000 \\ -1.037015 & -1.463244 & -0.000001 \\ -2.355851 & -1.024137 & -0.000002 \\ -2.629743 & 0.340827 & -0.000001 \\ -1.580195 & 1.256134 & 0.000000 \\ 0.806273 & 1.679946 & 0.000002 \\ 0.489432 & 2.588616 & 0.000003 \\ 1.319040 & -1.122492 & 0.000000 \\ 2.350422 & -0.444597 & 0.000002 \\ 3.395414 & -0.008407 & -0.000002 \\ -0.797915 & -2.519557 & -0.000002 \\ -3.163208 & -1.746153 & -0.000003 \\ -3.652501 & 0.698037 & -0.000001 \\ -1.783701 & 2.323281 & 0.000001\end{array}$

as-9

B3LYP $(E=-570.470642 ; \mathrm{ZPVE}=0.099307)$

$\begin{array}{lrrr}\mathrm{C} & -0.651871 & -0.729403 & 0.000000 \\ \mathrm{C} & 0.536322 & 0.014850 & 0.000006 \\ \mathrm{C} & 0.507597 & 1.408121 & 0.000004 \\ \mathrm{C} & -0.711976 & 2.071246 & -0.000003 \\ \mathrm{C} & -1.902879 & 1.350965 & -0.000009 \\ \mathrm{C} & -1.855172 & -0.030087 & -0.000007 \\ \mathrm{O} & -0.664322 & -2.083115 & 0.000002 \\ \mathrm{H} & 0.252699 & -2.394651 & 0.000008 \\ \mathrm{~N} & 1.712276 & -0.781975 & 0.000011 \\ \mathrm{~N} & 2.809740 & -0.222951 & 0.000008 \\ \mathrm{~N} & 3.863963 & 0.180351 & 0.000004 \\ \mathrm{H} & 1.434340 & 1.969106 & 0.000008 \\ \mathrm{H} & -0.736670 & 3.152991 & -0.000005 \\ \mathrm{H} & -2.867140 & 1.841886 & -0.000015 \\ \mathrm{~F} & -3.000292 & -0.738503 & -0.000013\end{array}$

CBS-QB3 $(E=-569.487174 ;$ ZPVE $=0.098506)$

$\begin{array}{rrr}0.650089 & -0.730728 & 0.000001 \\ -0.535992 & 0.021342 & -0.000002 \\ -0.503397 & 1.417256 & 0.000000 \\ 0.720691 & 2.075841 & 0.000005 \\ 1.909882 & 1.347518 & 0.000008 \\ 1.859961 & -0.035703 & 0.000006 \\ 0.653687 & -2.083220 & 0.000000 \\ -0.267411 & -2.379142 & -0.000004 \\ -1.712540 & -0.776172 & -0.000008 \\ -2.812256 & -0.222284 & -0.000010 \\ -3.872081 & 0.177125 & -0.000012 \\ -1.429628 & 1.980130 & -0.000003 \\ 0.751140 & 3.157983 & 0.000006 \\ 2.877590 & 1.832658 & 0.000012 \\ 3.001060 & -0.749968 & 0.000010\end{array}$


aa-9

B3LYP $(E=-570.469178 ;$ ZPVE $=0.099174)$

$\begin{array}{lrrr}\mathrm{C} & 0.660174 & -0.718145 & 0.000000 \\ \mathrm{C} & -0.559333 & -0.027028 & 0.000002 \\ \mathrm{C} & -0.561099 & 1.369645 & 0.000002 \\ \mathrm{C} & 0.631294 & 2.081276 & 0.000000 \\ \mathrm{C} & 1.850353 & 1.410504 & 0.000000 \\ \mathrm{C} & 1.830196 & 0.031745 & 0.000001 \\ \mathrm{O} & 0.674044 & -2.073894 & 0.000000 \\ \mathrm{H} & 1.592456 & -2.374724 & 0.000002 \\ \mathrm{~N} & -1.722968 & -0.829382 & 0.000004 \\ \mathrm{~N} & -2.818985 & -0.268991 & -0.000001 \\ \mathrm{~N} & -3.880423 & 0.118154 & -0.000005 \\ \mathrm{H} & -1.505123 & 1.900912 & 0.000004 \\ \mathrm{H} & 0.611659 & 3.163129 & -0.000002 \\ \mathrm{H} & 2.797567 & 1.933034 & -0.000001 \\ \mathrm{~F} & 2.995356 & -0.673072 & -0.000003\end{array}$

CBS-QB3 $(E=-569.529129 ;$ ZPVE $=0.098414)$

$\begin{array}{rrr}0.660198 & -0.719481 & 0.000000 \\ -0.560703 & -0.025767 & 0.000000 \\ -0.560731 & 1.373717 & 0.000000 \\ 0.633761 & 2.085822 & 0.000000 \\ 1.853932 & 1.411991 & 0.000000 \\ 1.833789 & 0.031027 & 0.000000 \\ 0.674182 & -2.074247 & 0.000000 \\ 1.594874 & -2.364212 & 0.000000 \\ -1.724509 & -0.828413 & 0.000001 \\ -2.821159 & -0.268921 & 0.000000 \\ -3.887840 & 0.114813 & -0.000001 \\ -1.505739 & 1.904421 & 0.000000 \\ 0.614975 & 3.168234 & 0.000000 \\ 2.803213 & 1.931632 & -0.000001 \\ 2.996923 & -0.679147 & 0.000000\end{array}$

\section{sa-9}

B3LYP $(E=-570.469343 ; \mathrm{ZPVE}=0.099036)$

$\begin{array}{lrrr}\mathrm{C} & -0.173711 & -0.521867 & -0.000001 \\ \mathrm{C} & 0.388485 & 0.762175 & -0.000006 \\ \mathrm{C} & -0.459980 & 1.873008 & 0.000001 \\ \mathrm{C} & -1.838240 & 1.722496 & 0.000003 \\ \mathrm{C} & -2.408325 & 0.451832 & -0.000001 \\ \mathrm{C} & -1.558671 & -0.632819 & 0.000000 \\ \mathrm{O} & 0.632427 & -1.618747 & 0.000005 \\ \mathrm{H} & 0.083471 & -2.413953 & -0.000005 \\ \mathrm{~N} & 1.769248 & 1.038169 & -0.000001 \\ \mathrm{~N} & 2.628585 & 0.149709 & 0.000000 \\ \mathrm{~N} & 3.548906 & -0.502162 & 0.000001 \\ \mathrm{H} & -0.007358 & 2.855785 & 0.000003 \\ \mathrm{H} & -2.474921 & 2.597373 & 0.000006 \\ \mathrm{H} & -3.478795 & 0.296168 & 0.000000 \\ \mathrm{~F} & -2.056260 & -1.901595 & -0.000001\end{array}$

CBS-QB3 $(E=-569.529865 ; \mathrm{ZPVE}=0.098204)$

$\begin{array}{rrr}-0.170769 & -0.521289 & 0.000000 \\ 0.388123 & 0.767052 & 0.000001 \\ -0.465574 & 1.877318 & 0.000002 \\ -1.845452 & 1.722015 & 0.000001 \\ -2.411687 & 0.446886 & 0.000000 \\ -1.558393 & -0.637872 & 0.000000 \\ 0.639356 & -1.614449 & 0.000000 \\ 0.087005 & -2.405785 & -0.000003 \\ 1.768613 & 1.043642 & 0.000002 \\ 2.625597 & 0.152929 & -0.000001 \\ 3.547183 & -0.503476 & -0.000002 \\ -0.012770 & 2.860444 & 0.000003 \\ -2.485622 & 2.595041 & 0.000002 \\ -3.481743 & 0.285599 & 0.000000 \\ -2.047662 & -1.910671 & -0.000001\end{array}$


$\mathbf{a -}{ }^{3} \mathbf{1 0}$

$\operatorname{B3LYP}(E=-460.906470 ; \mathrm{ZPVE}=0.087242) \quad \operatorname{CASSCF}(8,8)(E=-458.294809 ; \mathrm{ZPVE}=0.092045)$

Orbital occupation: 29 - 1.95; 30 - 1.89; 31 - 1.89; 32 - 1.00;

$33-1.00 ; 34-0.11 ; 35-0.12 ; 36-0.04$

$\begin{array}{lrrrrrr}\mathrm{C} & -0.169030 & -0.742130 & 0.000000 & 0.000000 & 0.759581 & 0.000000 \\ \mathrm{C} & 1.238506 & -0.458095 & -0.000001 & 1.294995 & 0.170564 & 0.000000 \\ \mathrm{C} & 1.644889 & 0.917825 & 0.000000 & 1.398225 & -1.252334 & 0.000000 \\ \mathrm{C} & 0.716908 & 1.931897 & 0.000000 & 0.264378 & -2.046989 & 0.000000 \\ \mathrm{C} & -0.656394 & 1.643440 & 0.000000 & -1.011878 & -1.459829 & 0.000000 \\ \mathrm{C} & -1.055344 & 0.320885 & 0.000000 & -1.104372 & -0.074421 & 0.000000 \\ \mathrm{O} & -0.576821 & -2.027133 & 0.000000 & -0.108218 & 2.100257 & 0.000000 \\ \mathrm{H} & -1.543810 & -2.052492 & 0.000000 & -1.023261 & 2.350722 & 0.000000 \\ \mathrm{~N} & 2.131575 & -1.427827 & 0.000000 & 2.398981 & 0.928436 & 0.000000 \\ \mathrm{H} & 2.706529 & 1.125413 & 0.000000 & 2.379580 & -1.687916 & 0.000000 \\ \mathrm{H} & 1.042872 & 2.964029 & 0.000000 & 0.356416 & -3.116776 & 0.000000 \\ \mathrm{H} & -1.405271 & 2.424316 & 0.000000 & -1.909574 & -2.047609 & 0.000000 \\ \mathrm{~F} & -2.380443 & 0.007518 & 0.000000 & -2.308707 & 0.513448 & 0.000000\end{array}$

$\mathbf{S}-{ }^{3} \mathbf{1 0}$

$\operatorname{B3LYP}(E=-460.907658 ; \mathrm{ZPVE}=0.087321) \quad \operatorname{CASSCF}(8,8)(E=-458.293127 ; \mathrm{ZPVE}=0.091971)$

Orbital occupation: 29 - 1.89; 30 - 1.95; $31-1.89 ; 32-1.00$;

$33-1.00 ; 34-0.11 ; 35-0.11 ; 36-0.04$

$\begin{array}{lrrrrrr}\mathrm{C} & -0.055429 & -0.758352 & 0.000000 & -2.023770 & 1.248816 & 0.083925 \\ \mathrm{C} & 1.281564 & -0.222297 & 0.000000 & -2.258265 & 0.555554 & 1.306119 \\ \mathrm{C} & 1.453497 & 1.201343 & 0.000000 & -2.728437 & -0.792268 & 1.267415 \\ \mathrm{C} & 0.358494 & 2.028438 & 0.000000 & -2.952792 & -1.415352 & 0.055546 \\ \mathrm{C} & -0.941994 & 1.496619 & 0.000000 & -2.719815 & -0.726584 & -1.149517 \\ \mathrm{C} & -1.123387 & 0.125100 & 0.000000 & -2.262661 & 0.584014 & -1.110542 \\ \mathrm{O} & -0.283584 & -2.085212 & 0.000000 & -1.581113 & 2.519317 & 0.045204 \\ \mathrm{H} & 0.565656 & -2.551163 & 0.000000 & -1.456710 & 2.861398 & 0.920615 \\ \mathrm{~N} & 2.296283 & -1.058997 & 0.000000 & -2.035153 & 1.175649 & 2.468399 \\ \mathrm{H} & 2.462380 & 1.591107 & 0.000000 & -2.899708 & -1.299414 & 2.198092 \\ \mathrm{H} & 0.491751 & 3.102657 & 0.000000 & -3.306277 & -2.428899 & 0.027616 \\ \mathrm{H} & -1.814574 & 2.136626 & 0.000000 & -2.886454 & -1.188326 & -2.103738 \\ \mathrm{~F} & -2.371888 & -0.378851 & 0.000000 & -2.044830 & 1.228435 & -2.250261\end{array}$


$\mathbf{a}^{\mathrm{OSS}} \mathbf{1 0}$

$\operatorname{CASSCF}(8,8)(E=-458.265910 ; \mathrm{ZPVE}=0.091230)$

Orbital occupation: 29 - 1.94; 30 - 1.91; 31 - 1.89; 32 - 1.00; 33 - 1.00; $34-0.10 ; 35-0.11 ; 36-0.05$

$\begin{array}{lrrr}\mathrm{C} & -0.225262 & 0.741431 & 0.000009 \\ \mathrm{C} & 1.230674 & 0.527714 & -0.000001 \\ \mathrm{C} & 1.700209 & -0.870447 & 0.000007 \\ \mathrm{C} & 0.813642 & -1.908819 & -0.000003 \\ \mathrm{C} & -0.594720 & -1.675665 & -0.000005 \\ \mathrm{C} & -1.052297 & -0.343743 & 0.000003 \\ \mathrm{O} & -0.658156 & 2.012529 & 0.000006 \\ \mathrm{H} & -1.607289 & 2.030892 & 0.000000 \\ \mathrm{~N} & 2.053491 & 1.502238 & -0.000019 \\ \mathrm{H} & 2.760651 & -1.032758 & 0.000011 \\ \mathrm{H} & 1.172625 & -2.921137 & 0.000001 \\ \mathrm{H} & -1.305158 & -2.478040 & -0.000007 \\ \mathrm{~F} & -2.373721 & -0.115297 & 0.000002\end{array}$

$\mathbf{S}^{-}{ }^{\mathrm{OSS}} \mathbf{1 0}$

$\operatorname{CASSCF}(8,8)(E=-458.264936 ; \mathrm{ZPVE}=0.090940)$

Orbital occupation: 29 - 1.89; 30 - 1.94; 31 - 1.91; 32 - 1.00; 33 - 1.00; 34 - 0.09; 35 - 0.11; 36 - 0.05

$\begin{array}{lrrr}\mathrm{C} & -2.017179 & 1.268339 & 0.056366 \\ \mathrm{C} & -2.252901 & 0.570573 & 1.332106 \\ \mathrm{C} & -2.737267 & -0.817931 & 1.275932 \\ \mathrm{C} & -2.954616 & -1.420909 & 0.071706 \\ \mathrm{C} & -2.719695 & -0.726132 & -1.153011 \\ \mathrm{C} & -2.255879 & 0.603649 & -1.113984 \\ \mathrm{O} & -1.574821 & 2.537277 & 0.049019 \\ \mathrm{H} & -1.458456 & 2.855870 & 0.934913 \\ \mathrm{~N} & -2.036743 & 1.171973 & 2.436872 \\ \mathrm{H} & -2.907713 & -1.322696 & 2.207002 \\ \mathrm{H} & -3.308171 & -2.434455 & 0.034914 \\ \mathrm{H} & -2.887056 & -1.189956 & -2.104701 \\ \mathrm{~F} & -2.045490 & 1.226738 & -2.268262\end{array}$


$\mathbf{a}^{-{ }^{C S S}} \mathbf{1 0}$

$\operatorname{CASSCF}(8,8)(E=-458.228879 ; \mathrm{ZPVE}=0.093165)$

Orbital occupation: 29 - 1.90; 30 - 1.96; 31 - 1.91; 32 - 1.62; 33 - 0.40; $34-0.03 ; 35$ - 0.08; 36 - 0.09

$\begin{array}{lrrr}\mathrm{C} & -0.130632 & 0.751156 & -0.000003 \\ \mathrm{C} & 1.242914 & 0.409400 & 0.000015 \\ \mathrm{C} & 1.599289 & -0.967194 & -0.000017 \\ \mathrm{C} & 0.640251 & -1.964749 & -0.000006 \\ \mathrm{C} & -0.719281 & -1.613022 & 0.000002 \\ \mathrm{C} & -1.071128 & -0.280218 & -0.000004 \\ \mathrm{O} & -0.512148 & 2.028759 & -0.000023 \\ \mathrm{H} & -1.459474 & 2.085920 & -0.000032 \\ \mathrm{~N} & 2.197094 & 1.364490 & 0.000039 \\ \mathrm{H} & 2.646880 & -1.201081 & -0.000036 \\ \mathrm{H} & 0.922972 & -3.000303 & -0.000012 \\ \mathrm{H} & -1.495140 & -2.355617 & 0.000012 \\ \mathrm{~F} & -2.362910 & 0.075260 & 0.000008\end{array}$

\section{TS-OH}

$\operatorname{B} 3 L Y P(E=-460.897541 ;$ ZPVE $=0.085957)$

$\begin{array}{lrrr}\mathrm{C} & 0.128349 & -0.753984 & 0.007462 \\ \mathrm{C} & -1.255103 & -0.364306 & 0.002683 \\ \mathrm{C} & -1.575211 & 1.032461 & -0.002343 \\ \mathrm{C} & -0.574532 & 1.977152 & -0.003988 \\ \mathrm{C} & 0.770717 & 1.592148 & -0.004227 \\ \mathrm{C} & 1.089744 & 0.239395 & 0.002361 \\ \mathrm{O} & 0.472770 & -2.071934 & 0.107190 \\ \mathrm{H} & 0.611667 & -2.467635 & -0.762091 \\ \mathrm{~N} & -2.215902 & -1.269358 & -0.007977 \\ \mathrm{H} & -2.619685 & 1.314171 & -0.003358 \\ \mathrm{H} & -0.825803 & 3.030352 & -0.005880 \\ \mathrm{H} & 1.571711 & 2.319718 & -0.007814 \\ \mathrm{~F} & 2.387498 & -0.119203 & -0.003802\end{array}$




\section{Z-311}

$\operatorname{B3LYP}(E=-460.908591 ; \mathrm{ZPVE}=0.086885) \quad \operatorname{CASSCF}(8,8)(E=-458.290950 ; \mathrm{ZPVE}=0.091681)$

Orbital occupation: 29 - 1.94; 30 - 1.91; 31 - 1.03; 32 - 1.88;

$33-0.97 ; 34-0.10 ; 35-0.12 ; 36-0.05$

$\begin{array}{lrrrrrr}\mathrm{C} & -0.076310 & -0.839142 & -0.000006 & -0.028622 & -0.831968 & -0.055221 \\ \mathrm{C} & -1.304504 & 0.000546 & 0.000000 & 1.298462 & -0.159732 & -0.028015 \\ \mathrm{C} & -1.161148 & 1.394963 & 0.000000 & 1.342238 & 1.237190 & 0.015609 \\ \mathrm{C} & 0.118120 & 2.029329 & 0.000000 & 0.136402 & 2.040726 & 0.035119 \\ \mathrm{C} & 1.269461 & 1.290108 & 0.000001 & -1.096202 & 1.446205 & 0.010729 \\ \mathrm{C} & 1.166740 & -0.119670 & -0.000002 & -1.174506 & 0.027287 & -0.034101 \\ \mathrm{O} & -0.128483 & -2.080594 & 0.000003 & -0.128065 & -2.057766 & -0.093291 \\ \mathrm{H} & -2.406085 & -1.563292 & -0.000002 & 2.205023 & -1.848094 & -0.076559 \\ \mathrm{~N} & -2.516086 & -0.542967 & 0.000001 & 2.427940 & -0.865764 & -0.044745 \\ \mathrm{H} & -2.063817 & 1.993542 & 0.000001 & 2.304710 & 1.710929 & 0.034383 \\ \mathrm{H} & 0.170507 & 3.110609 & 0.000001 & 0.222920 & 3.109906 & 0.069181 \\ \mathrm{H} & 2.251794 & 1.744115 & 0.000003 & -2.009102 & 2.010171 & 0.024246 \\ \mathrm{~F} & 2.290434 & -0.819584 & 0.000001 & -2.365191 & -0.532218 & -0.057329\end{array}$

\section{Z-11}

B3LYP $(E=-460.953305 ; \mathrm{ZPVE}=0.089351) \quad \operatorname{CASSCF}(8,8)(E=-458.356915 ; \mathrm{ZPVE}=0.094747)$

Orbital occupation: 29 - 1.92; 30 - 1.94; 31 - 1.85; 32 - 1.9;

$33-0.17 ; 34-0.05 ; 35-0.09 ; 36-0.08$

$\begin{array}{lrrrrrr}\mathrm{C} & -0.046141 & -0.854440 & -0.000004 & -0.039481 & -0.843419 & -0.000146 \\ \mathrm{C} & 1.320381 & -0.152972 & -0.000002 & 1.311954 & -0.168488 & -0.000033 \\ \mathrm{C} & 1.356654 & 1.305579 & -0.000001 & 1.351273 & 1.298539 & -0.000004 \\ \mathrm{C} & 0.215125 & 2.013844 & 0.000000 & 0.212530 & 2.023581 & -0.000003 \\ \mathrm{C} & -1.091474 & 1.374276 & 0.000002 & -1.108158 & 1.384223 & -0.000013 \\ \mathrm{C} & -1.212893 & 0.038017 & 0.000000 & -1.214840 & 0.045911 & -0.000046 \\ \mathrm{O} & -0.129200 & -2.064857 & -0.000001 & -0.140246 & -2.048775 & 0.000188 \\ \mathrm{H} & 2.156313 & -1.839169 & 0.000008 & 2.185982 & -1.836474 & -0.000042 \\ \mathrm{~N} & 2.395264 & -0.839753 & 0.000004 & 2.395416 & -0.850218 & 0.000020 \\ \mathrm{H} & 2.331017 & 1.776602 & -0.000004 & 2.321543 & 1.757095 & 0.000029 \\ \mathrm{H} & 0.241249 & 3.096408 & -0.000003 & 0.248109 & 3.096776 & 0.000034 \\ \mathrm{H} & -1.986353 & 1.985322 & 0.000005 & -1.996716 & 1.986834 & 0.000031 \\ \mathrm{~F} & -2.413932 & -0.551985 & 0.000001 & -2.391356 & -0.558713 & -0.000010\end{array}$




\section{TS-Hshift}

B3LYP $(E=-460.865278 ; \mathrm{ZPVE}=0.082345)$

$\begin{array}{lrrr}\mathrm{C} & 0.154803 & -0.728945 & -0.016784 \\ \mathrm{C} & 1.248903 & 0.211022 & 0.017665 \\ \mathrm{C} & 1.021546 & 1.605581 & -0.018370 \\ \mathrm{C} & -0.288619 & 2.028310 & -0.033104 \\ \mathrm{C} & -1.372528 & 1.116837 & -0.009296 \\ \mathrm{C} & -1.153840 & -0.244700 & 0.014701 \\ \mathrm{O} & 0.582398 & -1.968614 & -0.089607 \\ \mathrm{H} & 1.898004 & -1.594612 & -0.092381 \\ \mathrm{~N} & 2.360979 & -0.506004 & 0.095364 \\ \mathrm{H} & 1.849175 & 2.301878 & -0.013018 \\ \mathrm{H} & -0.509690 & 3.088116 & -0.037736 \\ \mathrm{H} & -2.392698 & 1.478968 & 0.001647 \\ \mathrm{~F} & -2.188046 & -1.101337 & 0.051326\end{array}$

\section{MECP}

B3LYP $(E=-460.888293 ; \mathrm{ZPVE}=0.0840) \quad \operatorname{CASSCF}(8,8)(E=-458.250949 ; \mathrm{ZPVE}=0.089486)$

Triplet Occupation: 29 - 1.89; 30 - 1.95; 31 - 1.91; 32 - 1.00;

$33-1.00 ; 34-0.10 ; 35-0.10 ; 36-0.04$

Singlet Occupation: 29 - 1.94; 30 - 1.97; 31 - 1.88; 32 - 1.91;

$33-0.13 ; 34-0.03 ; 35-0.07 ; 36-0.06$

$\begin{array}{lrrr}\mathrm{C} & 0.097463 & -0.758423 & 0.007280 \\ \mathrm{C} & 1.412020 & -0.053653 & 0.003939 \\ \mathrm{C} & 1.395259 & 1.396964 & 0.004944 \\ \mathrm{C} & 0.208741 & 2.059198 & 0.013092 \\ \mathrm{C} & -1.030607 & 1.346228 & 0.008278 \\ \mathrm{C} & -1.093131 & -0.019729 & 0.001573 \\ \mathrm{O} & 0.195628 & -2.041699 & 0.013844 \\ \mathrm{H} & 1.257062 & -2.097765 & 0.015605 \\ \mathrm{~N} & 2.421414 & -0.842784 & 0.003710 \\ \mathrm{H} & 2.346971 & 1.912342 & 0.001600 \\ \mathrm{H} & 0.172542 & 3.140690 & 0.019116 \\ \mathrm{H} & -1.965439 & 1.895893 & 0.009212 \\ \mathrm{~F} & -2.281917 & -0.650391 & 0.006190\end{array}$

$\begin{array}{rrr}0.114275 & -0.750916 & 0.008232 \\ 1.430873 & -0.062799 & 0.005876 \\ 1.401490 & 1.401969 & 0.005957 \\ 0.216953 & 2.060141 & 0.013471 \\ -1.051991 & 1.341828 & 0.009987 \\ -1.107538 & -0.010947 & 0.004802 \\ 0.193450 & -2.003310 & 0.011251 \\ 1.236337 & -2.089038 & 0.011595 \\ 2.412800 & -0.873229 & 0.005467 \\ 2.341534 & 1.919145 & 0.000316 \\ 0.176318 & 3.132976 & 0.017612 \\ -1.974550 & 1.892237 & 0.006859 \\ -2.253943 & -0.671188 & -0.005413\end{array}$




\section{References}

(S1) Pirali, T.; Gatti, S.; Di Brisco, R.; Tacchi, S.; Zaninetti, R.; Brunelli, E.; Massarotti, A.; Sorba, G.; Canonico, P. L.; Moro, L.; Genazzani, A. A.; Tron, G. C.; Billington, R. A. Estrogenic Analogues Synthesized by Click Chemistry. ChemMedChem 2007, 2, 437-440.

(S2) Vosko, S. H.; Wilk, L.; Nusair, M. Accurate Spin-Dependent Electron Liquid Correlation Energies for Local Spin Density Calculations: A Critical Analysis. Can. J. Phys. 1980, 58, $1200-1211$.

(S3) Lee, C.; Yang, W.; Parr, R. G. Development of the Colle-Salvetti Correlation-Energy Formula into a Functional of the Electron Density. Phys. Rev. B 1988, 37, 785-789.

Becke, A. D. Density-Functional Thermochemistry. III. The Role of Exact Exchange. J. Chem. Phys. 1993, 98, 5648-5652.

(S5) Frisch, M. J.; Pople, J. A.; Binkley, J. S. Self-Consistent Molecular Orbital Methods 25. Supplementary Functions for Gaussian Basis Sets. J. Chem. Phys. 1984, 80, 3265-3269.

(S6) Frisch, M. J.; Trucks, G. W.; Schlegel, H. B.; Scuseria, G. E.; Robb, M. A.; Cheeseman, J. R.; Scalmani, G.; Barone, V.; Petersson, G. A.; Nakatsuji, H.; Li, X.; Caricato, M.; Marenich, A. V.; Bloino, J.; Janesko, B. G.; Gomperts, R.; Mennucci, B.; Hratchian, H. P.; Ortiz, J. V.; Izmaylov, A. F.; Sonnenberg, J. L.; Williams-Young, D.; Ding, F.; Lipparini, F.; Egidi, F.; Goings, J.; Peng, B.; Petrone, A.; Henderson, T.; Ranasinghe, D.; Zakrzewski, V. G.; Gao, J.; Rega, N.; Zheng, G.; Liang, W.; Hada, M.; Ehara, M.; Toyota, K.; Fukuda, R.; Hasegawa, J.; Ishida, M.; Nakajima, T.; Honda, Y.; Kitao, O.; Nakai, H.; Vreven, T.; Throssell, K.; Montgomery, J. A., Jr.; Peralta, J. E.; Ogliaro, F.; Bearpark, M. J.; Heyd, J. J.; Brothers, E. N.; Kudin, K. N.; Staroverov, V. N.; Keith, T. A.; Kobayashi, R.; Normand, J.; Raghavachari, K.; Rendell, A. P.; Burant, J. C.; Iyengar, S. S.; Tomasi, J.; Cossi, M.; Millam, J. M.; Klene, M.; Adamo, C.; Cammi, R.; Ochterski, J. W.; Martin, R. L.; Morokuma, K.; Farkas, O.; Foresman, J. B.; Fox, D. J. Gaussian 16, Revision B.01; Gaussian, Inc.: Wallingford CT, 2016.

(S7) Nunes, C. M.; Eckhardt, A. K.; Reva, I.; Fausto, R.; Schreiner, P. R. Competitive Nitrogen versus Carbon Tunneling. J. Am. Chem. Soc. 2019, 141, 14340-14348.

(S8) Barone, V.; Bloino, J.; Guido, C. A.; Lipparini, F. A Fully Automated Implementation of VPT2 Infrared Intensities. Chem. Phys. Lett. 2010, 496, 157-161. 
(S9) Bloino, J.; Barone, V. A Second-Order Perturbation Theory Route to Vibrational Averages and Transition Properties of Molecules: General Formulation and Application to Infrared and Vibrational Circular Dichroism Spectroscopies. J. Chem. Phys. 2012, 136, 124108.

(S10) Barone, V.; Biczysko, M.; Bloino, J. Fully Anharmonic IR and Raman Spectra of MediumSize Molecular Systems: Accuracy and Interpretation. Phys. Chem. Chem. Phys. 2014, 16, 1759-1787.

(S11) Montgomery, J. A.; Frisch, M. J.; Ochterski, J. W.; Petersson, G. A. A Complete Basis Set Model Chemistry. VI. Use of Density Functional Geometries and Frequencies. J. Chem. Phys. 1999, 110, 2822-2827.

(S12) Montgomery, J. A.; Frisch, M. J.; Ochterski, J. W.; Petersson, G. A. A Complete Basis Set Model Chemistry. VII. Use of the Minimum Population Localization Method. J. Chem. Phys. 2000, 112, 6532-6542.

(S13) Schachtschneider, J. H.; Mortimer, F. S. Vibrational Analysis of Polyatomic Molecules. VI. FORTRAN IV Programs for Solving the Vibrational Secular Equation and for the LeastSquares Refinement of Force Constants, Structural Interpretation Of Spectra. Shell Development Co., Emeryville, CA, 1969.

(S14) Pulay, P.; Fogarasi, G.; Pang, F.; Boggs, J. E. Systematic AB Initio Gradient Calculation of Molecular Geometries, Force Constants, and Dipole Moment Derivatives. J. Am. Chem. Soc. 1979, 101, 2550-2560.

(S15) Karney, W. L.; Borden, W. T. Ab Initio Study of the Ring Expansion of Phenylnitrene and Comparison with the Ring Expansion of Phenylcarbene. J. Am. Chem. Soc. 1997, 119, $1378-1387$.

(S16) Smith, K. M.; Poli, R.; Harvey, J. N. Ligand Dissociation Accelerated by Spin State Change: Locating the Minimum Energy Crossing Point for Phosphine Exchange in $\left.\mathrm{CpMoCl} \mathrm{PR}_{2}\right)_{2}$ Complexes. New J. Chem. 2000, 24, 77-80.

(S17) Harvey, J. N. Understanding the Kinetics of Spin-Forbidden Chemical Reactions. Phys. Chem. Chem. Phys. 2007, 9, 331-343.

(S18) Rodríguez-Guerra, J.; Funes-Ardoiz, I.; Maseras, F. EasyMECP. Zenodo 2018.

(S19) Harvey, J. N.; Aschi, M.; Schwarz, H.; Koch, W. The Singlet and Triplet States of Phenyl Cation. A Hybrid Approach for Locating Minimum Energy Crossing Points between NonInteracting Potential Energy Surfaces. Theor. Chem. Acc. 1998, 99, 95-99. 
(S20) Gannon, K. L.; Blitz, M. A.; Liang, C. H.; Pilling, M. J.; Seakins, P. W.; Glowacki, D. R.; Harvey, J. N. An Experimental and Theoretical Investigation of the Competition between Chemical Reaction and Relaxation for the Reactions of ${ }^{1} \mathrm{CH}_{2}$ with Acetylene and Ethene: Implications for the Chemistry of the Giant Planets. Faraday Discuss. 2010, 147, 173-188.

(S21) Viegas, L. P.; M. Nunes, C.; Fausto, R. Spin-Forbidden Heavy-Atom Tunneling in the RingClosure of Triplet Cyclopentane-1,3-Diyl. Phys. Chem. Chem. Phys. 2021, 23, 5797-5803.

(S22) Vyas, S.; Winter, A. H.; Hadad, C. M. Chapter 2. Theory and Computation in the Study of Nitrenes and Their Excited-State Photoprecursors. In Nitrenes and Nitrenium ions; Falvey, D. E., Gudmundsdottir, A. D., Eds.; Wiley, 2013; pp 33-76.

(S23) Wentzel, G. Eine Verallgemeinerung Der Quantenbedingungen Für Die Zwecke Der Wellenmechanik. Zeitschrift für Phys. 1926, 38, 518-529.

(S24) Kramers, H. A. Wellenmechanik Und Halbzahlige Quantisierung. Zeitschrift für Phys. 1926, 39, 828-840.

(S25) Brilluoin, L. La Mécanique Ondulatoire de Schrödinger; Une Méthode Générale de Résolution Par Approximations Successives. C. R. Acad. Sci 1926, 183, 24-26.

(S26) Delos, J. B. On the Reactions of $\mathrm{N}_{2}$ with O. J. Chem. Phys. 1973, 59, 2365-2369.

(S27) Landau, L. D.; Lifshitz, E. M. Quantum Mechanics. Non-Relativistic Theory; (Pergamon Press Ltd., Oxford, England), Second (Revised) Edition, 1965.

(S28) Coveney, P. V.; Child, M. S.; Bárány, A. The Two-State S Matrix for the Landau-Zener Potential Curve Crossing Model: Predissociation and Resonant Scattering. J. Phys. B At. Mol. Phys. 1985, 18, 4557-4580.

(S29) Harvey, J. N.; Aschi, M. Spin-Forbidden Dehydrogenation of Methoxy Cation: A Statistical View. Phys. Chem. Chem. Phys. 1999, 1, 5555-5563.

(S30) Tully, J. C. Collision Complex Model for Spin Forbidden Reactions: Quenching of O( $\left({ }^{1} \mathrm{D}\right)$ by $\mathrm{N}_{2}$. J. Chem. Phys. 1974, 61, 61-68.

(S31) Zahr, G. E.; Preston, R. K.; Miller, W. H. Theoretical Treatment of Quenching in O $\left({ }^{1} \mathrm{D}\right)+$ $\mathrm{N}_{2}$ Collisions. J. Chem. Phys. 1975, 62, 1127-1135.

(S32) Heller, E. J.; Brown, R. C. Radiationless Transitions in a New Light. J. Chem. Phys. 1983, 79, 3336-3351.

(S33) Lorquet, J. C.; Leyh-Nihant, B. Nonadiabatic Unimolecular Reactions. 1. A Statistical Formulation for the Rate Constants. J. Phys. Chem. 1988, 92, 4778-4783. 
(S34) Cui, Q.; Morokuma, K.; Bowman, J. M.; Klippenstein, S. J. The Spin-Forbidden Reaction Nonadiabatic Transition State Theory and Application. J. Chem. Phys. 1999, 110, 94699482.

(S35) Nunes, C. M.; Viegas, L. P.; Wood, S. A.; Roque, J. P. L.; McMahon, R. J.; Fausto, R. Heavy-Atom Tunneling Through Crossing Potential Energy Surfaces: Cyclization of a Triplet 2-Formylarylnitrene to a Singlet 2,1-Benzisoxazole. Angew. Chem. Int. Ed. 2020, 59, 17622-17627.

(S36) Chiodo, S.; Russo, N. Determination of Spin-Orbit Coupling Contibutions in the Framework of Density Functional Theory. J. Comput. Chem. 2008, 29, 912-920.

(S37) Chiodo, S. G.; Russo, N. One Electron Spin Orbit Contribution by Effective Nuclear Charges. J. Comput. Chem. 2009, 30, 832-839.

(S38) Chiodo, S. G.; Leopoldini, M. MolSOC: A Spin-Orbit Coupling Code. Comput. Phys. Commun. 2014, 185, 676-683. 